\title{
Efetividade ambiental e socioeconômica de 20 anos do Programa de Adequação Ambiental e Agrícola (LERF/LCB/ESALQ/USP) no Estado de São Paulo, Brasil ${ }^{1}$
}

\author{
Steve de Oliveira Costa ${ }^{2,5}$, (1) Priscila Orlandini² ${ }^{2}$ (1) Letícia Ribes de Lima $^{3}$ e (D) Ricardo Ribeiro Rodrigues ${ }^{4}$
}

Recebido: 11.05.2020; aceito: 01.09.2020

Como citar: Costa, S.O., Orlandini, P., Lima, L.R., \& Rodrigues, R.R. 2020. Efetividade ambiental e socioeconômica de 20 anos do Programa de Adequação Ambiental e Agrícola (LERF/LCB/ESALQ/USP) no Estado de São Paulo, Brasil. Hoehnea 47: e482020. http://dx.doi.org/10.1590/2236-8906-48/2020.

\begin{abstract}
Environmental and socioeconomic effectiveness of 20 years of the Programa de Adequação Ambiental e Agrícola (LERF/LCB/ESALQ/USP) in São Paulo State, Brazil). In the context of biological conservation, the high levels of environmental degradation has mainly originated from the historic expansion of the Brazilian agricultural frontier, phenomenon particularly intense in the Atlantic Forest. The Laboratório de Ecologia e Restauração Florestal of the Universidade de São Paulo has been developing, since 1998, the Programa de Adequação Ambiental e Agrícola de Propriedades Rurais (PAAA). The research's goal was to evaluate the environmental and socioeconomic effectiveness of the developed program, identifying its main successes and failures. After evaluating the program, it was established that it has obtained several environmental and socioeconomic benefits, such as the production from 60,000 to 300,000 seedlings, the generation of 106 jobs and the annual donation of 16,000 to 120,000 seedlings per program. The results of the evaluated PAAA can be used as a subsidy to strengthen the pressure for the creation of public policies to enhance the agricultural and environmental regularization actions in the State of São Paulo and in rural properties located in other States of Brazil.
\end{abstract}

Keywords: ecology, environmental planning, forest code, forest restoration, protected areas

RESUMO - (Efetividade ambiental e socioeconômica de 20 anos do Programa de Adequação Ambiental e Agrícola (LERF/ LCB/ESALQ/USP) no Estado de São Paulo, Brasil). No contexto da conservação biológica, os elevados níveis de degradação ambiental têm como origem principal a expansão histórica da fronteira agrícola brasileira, fenômeno particularmente intenso na Mata Atlântica. Neste contexto, o Laboratório de Ecologia e Restauração Florestal da Universidade de São Paulo desenvolve, desde 1998, o Programa de Adequação Ambiental e Agrícola de Propriedades Rurais (PAAA). O objetivo deste trabalho foi realizar uma avaliação da efetividade ambiental e socioeconômica do citado programa, identificando seus principais sucessos e deficiências. Após a avaliação, verificou-se que o programa obteve benefícios ambientais e socioeconômicos diversos, como a produção de 60,000 a 300,000 mudas de espécies nativas por propriedade, além da geração de 106 empregos diretos e a doação anual de 16,000 a 120,000 mudas. Os resultados do PAAA implantado em diferentes propriedades servem como subsídio para fortalecer a pressão pela criação de políticas públicas para potencializar as ações de regularização ambiental e agrícola tanto no Estado de São Paulo, quanto em propriedades rurais localizadas em outros Estados do Brasil.

Palavras-chave: áreas protegidas, código florestal, ecologia, planejamento ambiental, restauração florestal

1. Parte da Dissertação de Mestrado do primeiro Autor

2. Universidade Estadual de Campinas, Instituto de Biologia, Rua Monteiro Lobato, 255, Barão Geraldo, 13083-862 Campinas, SP, Brasil

3. Universidade Federal de Alagoas, Instituto de Ciências Biológicas e da Saúde, campus A.C. Simões, Avenida Lourival Melo Mota, s/n, Cidade Universitária, 57072-900 Maceió, AL, Brasil

4. Universidade de São Paulo, Escola Superior de Agricultura Luiz de Queiroz, Departamento de Ciências Biológicas, Laboratório de Ecologia e Restauração Florestal, Avenida Pádua Dias, 11, 13.418-900 Piracicaba, SP, Brasil

5. Autor para correspondência: steve.costa.soc@gmail.com 


\section{Introdução}

O processo de expansão da fronteira agrícola na Mata Atlântica e as ações adotadas para a conservação e restauração da biodiversidade - As florestas tropicais destacam-se dentre os vários ecossistemas existentes no país, por possuírem mundialmente os maiores índices de biodiversidade e de endemismos (Myers et al. 2000). Esse fenômeno ressalta a necessidade de ações voltadas para a conservação e restauração dessa biodiversidade, bem como para a manutenção de seus serviços ecossistêmicos (Brancalion et al. 2013).

Os serviços ecossistêmicos, que representam as contribuições que os ecossistemas trazem ao bem-estar humano (Brockerhoffi et al. 2017), são amplamente fornecidos pelas florestas tropicais (Brancalion et al. 2015). Como exemplo, podem ser citados a regulação do clima, o fornecimento e a purificação da água, o controle da erosão, o sequestro de carbono, os serviços culturais, a polinização das culturas agrícolas e a provisão de hábitats para as espécies florestais (Brancalion et al. 2012).

Apesar da importância biológica dessas florestas, ao longo da história parte delas foi substituída por atividades de produção (Reis et al. 2003). Não obstante, esse ecossistema continua a ser destruído e fragmentado ainda hoje pela ação antrópica visando à produção agropecuária, o que tem levado a alarmantes taxas de perda de biodiversidade (Myers et al. 2000).

No Estado de São Paulo, a área total remanescente de cobertura florestal corresponde a $22,9 \%$ da que existia no fim do século XIX (Instituto Florestal 2020), sendo substituída pela ocupação para a produção agropecuária (Maury 2002). Nesse processo, a vegetação original foi drasticamente reduzida (Ramos et al. 2008). De rigor notar, portanto, que a expansão das áreas agrícolas trouxe impactos aos ecossistemas nativos, resultando na destruição de hábitats com elevada diversidade de recursos biológicos (Joly et al. 2008, Campanili \& Schaffer 2010).

Em função dessa alta demanda por terras para a produção agrícola, a cobertura vegetal remanescente está restrita a pequenos fragmentos florestais distantes entre si (Latawiec et al. 2015). Nesse cenário, a ciência da restauração ecológica visa ao restabelecimento da diversidade de espécies, bem como à reconstrução da estrutura e dos processos ecológicos complexos da comunidade (Silva et al. 2015).

Diante desses desafios, para que as áreas degradadas possam efetivamente ser convertidas em comunidades autossustentáveis, a ciência da ecologia de restauração tem se preocupado com uma visão integrada das relações ecológicas (SER 2004). Essa nova visão tem buscado elevar a riqueza e diversidade de espécies nativas nas áreas em processo de recuperação ambiental (Ayres et al. 2005). Ademais, tem-se almejado a manutenção das interações ecológicas viáveis a longo prazo, bem como a sustentabilidade ambiental e agrícola das propriedades (Brancalion et al. 2009).
Embora o objetivo primário da restauração florestal seja ecológico, não há como sustentá-lo na prática sem uma abordagem conjunta dos aspectos ecológicos, socioeconômicos e de gestão de projetos. Esse tratamento da matéria possibilita transformar métodos e conceitos da ecologia de restauração em projetos de recuperação ecológica bem-sucedidos no campo (Pacto pela Restauração da Mata Atlântica 2013).

Histórico de alterações do Código Florestal Brasileiro, que definem o cumprimento do Programa de Adequação Ambiental e Agrícola de Propriedades Rurais - O Código Florestal Brasileiro foi estabelecido por meio do Decreto $\mathrm{n}^{\circ}$ 23.793 de 1934, sendo modificado posteriormente por outros instrumentos legais, como a Lei $\mathrm{n}^{\circ} 4.771$ de 1965 e os ajustes propostos pela Lei $\mathrm{n}^{\circ} 12.651$, de 25 de maio de 2012 (Brasil 1934, Brasil 1965, Brasil 2012). Tal diploma determina o regime jurídico para a conciliação da preservação ambiental e do manejo sustentável dos recursos naturais, com o uso e ocupação do solo pelo homem para a produção agrícola (Brancalion \& Rodrigues 2010, Garcia et al. 2016).

Dentre o conjunto de medidas contidas na Lei de Proteção da Vegetação Nativa (Brasil 2012), destacamse as Áreas de Preservação Permanente (APPs) e as de Reserva Legal (RL), que estabelecem normas para que as atividades de produção agropecuária possam ser conduzidas, resguardando-se a conservação da biodiversidade e a geração de serviços ecossistêmicos (Brancalion \& Rodrigues 2010, Gatica-Saavedra et al. 2017).

A Lei Federal $n^{\circ} 12.651 / 12$ define as APPs como áreas protegidas, sejam cobertas ou não por vegetação nativa, que possuem a função ambiental de preservar os recursos hídricos, a paisagem, a estabilidade geológica e a biodiversidade, bem como de facilitar o fluxo gênico da fauna e flora, proteger o solo e assegurar o bem-estar das populações humanas (Brasil 2012).

A delimitação das APPs, definida no artigo $4^{\circ}$, da LPVN, tem o intuito de preservar locais frágeis que não podem ser desmatados a fim de se evitar erosões e deslizamentos, como beiras de rios, topos de morros e encostas. Além disso, tais áreas protegem as nascentes, a fauna, a flora e a biodiversidade (Falkenmark et al. 2014).

As exigências da legislação ambiental incluem a preservação e/ou a restauração da vegetação nas APPs, localizadas em regiões com declividade superior a $45^{\circ}$, em topos de morro e em margens dos corpos d'água, que podem variar de 30 a $500 \mathrm{~m}$, de acordo com as características da acumulação hídrica (Tambosi et al. 2012).

A RL possui seu conceito definido pelo artigo $3^{\circ}$, da Lei Federal $n^{\circ} 12.651 / 12$. Trata-se de área localizada no interior de uma propriedade ou posse rural que possui como funções, assegurar o uso econômico, de modo sustentável, dos recursos naturais presentes no imóvel rural, auxiliar a conservação e a reabilitação dos processos ecológicos e promover a conservação da biodiversidade (Brasil 2012). 
Além disso, destina-se ao abrigo e à proteção da fauna silvestre e da flora nativa (Brancalion et al. 2015).

No Estado de São Paulo, em propriedades e posses rurais com mais de quatro módulos fiscais, os proprietários deverão preservar ou recompor $20 \%$ de sua área como RL (Brasil 2012). De acordo com a LPVN, as propriedades não vinculadas ao licenciamento ambiental devem fazer a proposta de localização da RL diretamente no CAR.

Diante desse cenário, a avaliação da efetividade ambiental e socioeconômica do Programa de Adequação Ambiental e Agrícola, proposto pelo LERF/LCB/ESALQ/ USP e implantado em propriedades rurais localizadas no Estado de São Paulo, trata-se de um importante instrumento de gestão integrada destas empresas, já que permite ampliar a eficiência de seu controle por parte dos órgãos ambientais, além de estimulá-las à uma visão crítica de seu desempenho e à melhoria contínua de seus processos produtivos, que tendem a se consolidar progressivamente na legislação ambiental (Rovere 2014).

O objetivo deste trabalho de pesquisa foi realizar uma avaliação da efetividade ambiental e socioeconômica do Programa de Adequação Ambiental e Agrícola de Propriedades Rurais, do Laboratório de Ecologia e Restauração Florestal do LCB/ESALQ/USP, implantado em propriedades rurais no Estado de São Paulo.

O propósito principal foi identificar as conformidades e não conformidades desse programa, tanto em termos da conscientização dos gestores ou responsáveis ambientais para a importância das questões ambientais e socioeconômicas dentro da propriedade rural, quanto da efetividade das ações de restauração florestal estabelecidas nessas propriedades rurais, para a recuperação da vegetação nativa e o provimento de serviços ecossistêmicos, visando à proposição de aperfeiçoamentos do PAAA para potencializar a adequação ambiental e agrícola dessas propriedades rurais.

O Programa de Adequação Ambiental e Agrícola de Propriedades Rurais do Laboratório de Ecologia e Restauração Florestal do LCB/ESALQ/USP - No contexto da conservação e restauração de espécies nativas, o Laboratório de Ecologia e Restauração Florestal (LERF), do Departamento de Ciências Biológicas na Escola Superior de Agricultura Luiz de Queiroz da Universidade de São Paulo (LCB/ESALQ/USP), tem atuado praticando a conservação dos remanescentes naturais e a restauração ecológica de áreas degradadas, dentro do contexto de adequação ambiental e agrícola, por considerar que o bom planejamento ambiental e agrícola de propriedades rurais permite integrar as questões ambientais e de produção na paisagem rural (Myers et al. 2000, Rodrigues et al. 2007a, Rother et al. 2018).

O Programa de Adequação Ambiental e Agrícola de Propriedades Rurais (PAAA) foi desenvolvido pelo LERF, na perspectiva de demonstrar que é possível ter alta produtividade agrícola com sustentabilidade ambiental (Rodrigues et al. 2007b). Assim, percebe-se que o desafio da agricultura brasileira é a produção agropecuária de qualidade, lucrativa, em uma paisagem com elevada diversidade natural (Tambosi et al. 2012). Nesse cenário, por meio de convênios estabelecidos entre o LERF e empresas, organizações governamentais e não governamentais, teve início, em meados de 1998, o PAAA (Vidal et al. 2014).

O propósito desse programa foi demonstrar que a adequação as exigências da legislação ambiental poderiam beneficiar inclusive a própria atividade produtiva, por meio dos processos ecológicos (polinização, controle biológico, entre outros) e da certificação ambiental (Rodrigues et al. 2017).

Portanto, o PAAA tem como proposta central promover a tecnificação das áreas de alta aptidão agrícola, visando aumentar a sua produtividade (Rodrigues et al. 2007a). Também almeja incentivar o manejo sustentável das áreas de baixa aptidão agrícola e garantir a regularização ambiental destas propriedades, gerando, dentre outros serviços ecossistêmicos, benefícios à conservação dos recursos hídricos e do solo (Rodrigues et al. 2016).

A fase inicial desse programa diz respeito ao diagnóstico ambiental das propriedades rurais (Tambosi et al. 2012). Tal análise visa a identificar as regularidades e irregularidades em relação à legislação ambiental, bem como indicar as intervenções de restauração necessárias (Vidal et al. 2014).

Essa medida tornou-se obrigatória para todas as propriedades rurais no Brasil com a criação da Lei de Proteção da Vegetação Nativa (LPVN) (Lei n 12.651/12) (Brancalion et al. 2015), denominada popularmente de Novo Código Florestal Brasileiro, que modificou o Código Florestal anterior (Lei $\mathrm{n}^{\circ} 4.771 / 65$ ). Vale ressaltar que essa nova lei resultou em muitos retrocessos e alguns poucos avanços ambientais (Brancalion et al. 2016). É possível apontar, como consequências dessas alterações legislativas, a diminuição da proteção da vegetação nativa remanescente, a redução das áreas a serem restauradas e a permissão de exploração de áreas com elevada fragilidade ambiental nas propriedades públicas e privadas (Garcia et al. 2016).

Dentre os poucos avanços, nesse novo regime legal, foi criado o Cadastro Ambiental Rural (CAR), no qual todas as propriedades rurais no Brasil aderiram até dezembro de 2018, com o objetivo de promover o diagnóstico ambiental dessas propriedades perante a nova lei ambiental (Brasil 2012).

Nesse novo contexto, as propriedades rurais que apresentarem passivos ambientais deverão aderir ao Programa de Regularização Ambiental (PRA). Para tanto, será gerado o Projeto de Recomposição de Áreas Degradadas e Alteradas (PRADA), no qual a propriedade se compromete legalmente com a regularização do passivo em um prazo definido em lei, geralmente 20 anos (Garcia et al. 2016). O PRA e PRADA são estaduais e deverão se iniciar em janeiro de 2020 (Brasil 2012).

O Projeto de Recomposição de Áreas Degradadas e Alteradas consiste no instrumento de definição e de execução das ações de recuperação das áreas degradadas específico de cada terreno rural (Brancalion et al. 2016). Neste, o 
proprietário rural explicita as ações que serão realizadas para adequar seu imóvel à LPVN, indicando os insumos necessários, o cronograma esperado e a metodologia a ser utilizada (CAIP 2016).

Estes instrumentos legais constituem o conjunto de ações e iniciativas a serem desenvolvidas pelos proprietários e posseiros rurais, objetivando-se a adequação das propriedades e a sua regularização ambiental (Lima \& Munhoz 2016). Todo esse processo é semelhante ao que o Laboratório de Ecologia e Restauração Florestal do LCB/ESALQ/USP já vem realizando desde 1998, com seu PAAA, destacando que nesse programa são incluídas também avaliações da sustentabilidade agrícola da propriedade, integrada com as questões ambientais, o que na lei ambiental não é considerado (Rodrigues et al. 2016).

Diante do exposto, verifica-se que o esforço científico em se desenvolver a restauração ecológica no Brasil já teve alguns importantes avanços. Observa-se também uma tendência de transição, no caso, da elaboração de projetos isolados para a formulação e implementação de programas de longo prazo.

Nesse cenário, a proposição de programas de adequação ambiental e agrícola em propriedades rurais (Rodrigues et al. 2007b), aliada à avaliação periódica de sua efetividade ambiental e socioeconômica, permite auxiliar o controle do atendimento de políticas públicas nas propriedades em questão (Brasil 2012, Viani et al. 2017), na medida em que possibilita a identificação ao longo do processo das conformidades e não conformidades do projeto frente à legislação ambiental (Campos \& Lerípio 2009). Proporciona às empresas, ainda, a oportunidade de tomar as medidas necessárias à correção das não adequações detectadas, encaminhando-as ao cumprimento de suas metas legais (Rovere 2014).

Diante de toda a complexidade envolvida no restabelecimento do ecossistema nativo em uma área degradada, o desenvolvimento do processo de avaliação ambiental e socioeconômica nas propriedades rurais atendidas pelo PAAA do LERF/LCB/ESALQ/USP é essencial para a manutenção da sustentabilidade ambiental e agrícola destas propriedades (Rodrigues et al. 2007a).

O Programa de Adequação Ambiental e Agrícola de Propriedades Rurais (PAAA), desenvolvido pelo Laboratório de Ecologia e Restauração Florestal do LCB/ESALQ/USP, era denominado, inicialmente, de Programa de Adequação Ambiental (PAA). Sucede que, nos primórdios, não estava clara a necessidade premente de integrar as questões ambientais com as questões agrícolas dentro da propriedade rural. Não se atentava, portanto, para a interdependência desses aspectos na paisagem rural, que se dá inclusive para a provisão de serviços ecossistêmicos (Rodrigues et al. 2007a). Tanto o PAA, quanto o PAAA, caracterizam-se por apresentar as seguintes fases consecutivas de desenvolvimento (Vidal et al. 2014):
A. Diagnóstico ambiental das propriedades rurais: nesta fase inicial são identificadas as regularidades e irregularidades ambientais de cada propriedade rural, ou seja, é realizado o diagnóstico ambiental da propriedade dentro da perspectiva da definição da metodologia mais adequada de restauração para cada situação de degradação. Esse estágio do PAAA corresponde ao que foi definido na legislação atual (Lei ${ }^{\circ}$ 12.651, de maio de 2012) como Cadastro Ambiental Rural (CAR), voltado à identificação dos passivos ambientais de todas as propriedades rurais do Brasil.

B. Proposição de metodologias mais recomendadas de restauração para cada situação de passivo ambiental da propriedade: em função do diagnóstico realizado para cada situação de passivo ambiental das propriedades rurais, é feita a proposição do método mais adequado de restauração em termos de sucesso e custo. Para isso, são identificados, durante a primeira fase do programa, os usos passados e atuais da área degradada a ser restaurada, bem como as características da paisagem regional em termos de cobertura natural remanescente.

C. Levantamento florístico dos remanescentes florestais existentes nas propriedades: essa etapa não se volta apenas ao reconhecimento do tipo vegetacional dominante na propriedade e na região, mas também à definição das espécies mais adequadas a serem utilizadas na restauração de cada situação de degradação da propriedade, nos casos onde a metodologia indicada exija o plantio de espécies nativas. Para tanto, é feito o levantamento florístico regional nos fragmentos florestais remanescentes, cuja lista de espécies, organizadas em grupos funcionais de plantio, comporá um dos itens do PRADA (Projeto de Recomposição de Áreas Degradadas e Alteradas).

D. Marcação de matrizes para a coleta de sementes e implantação de viveiro comunitário para a produção de mudas de espécies nativas: a partir da listagem da flora de ocorrência regional, identificada na fase anterior (Fase C), são definidas as espécies nativas mais adequadas para o uso na restauração das áreas degradadas das propriedades objetos do programa, que necessitem do plantio de mudas ou sementes.

A lista de espécies é organizada em grupos funcionais, contendo espécies de recobrimento ou sombreadoras, atrativas de fauna, acumuladoras de carbono, em risco de extinção local, de diferentes estratos da floresta, etc. Nessa etapa, é favorecida ou mesmo recomendada a organização das propriedades em sindicatos rurais ou associações de produtores, pois a ação coletiva e organizada, na solução dos problemas ambientais, é a mais recomendada, por garantir maior sucesso com menor custo.

Sendo assim, a produção de sementes e mudas que serão usadas na regularização ambiental das propriedades rurais de uma dada região é viabilizada por meio da implantação de um viveiro coletivo para a produção de mudas de espécies nativas regionais, permitindo não apenas a redução de custos da regularização, como também a maior probabilidade de sucesso dessa iniciativa. 
E. Implantação de trilhas educativas: essa etapa representa uma ampliação do objetivo de marcação de matrizes para a coleta de sementes de espécies regionais, pois dentre os ambientes onde são marcadas matrizes, são escolhidos aqueles de elevada beleza cênica para a implantação de trilhas educativas no campo. Nessas trilhas, são marcados indivíduos de algumas espécies nativas de interesse, que são alvo da elaboração de material didático para o desenvolvimento de atividades de educação ambiental. Esse material possui fotos e descrições das espécies, curiosidades e usos, sua distribuição na área e outras informações de interesse.

\section{Material e métodos}

Área de estudo e métodos aplicados para coleta de dados no processo de avaliação da efetividade ambiental e socioeconômica do Programa de Adequação Ambiental e Agrícola - A avaliação do Programa de Adequação Ambiental e Agrícola de Propriedades Rurais foi desenvolvida a partir de projetos realizados em 12 empresas, nas quais a gestão administrativa autorizou a participação junto a este estudo. Estas 12 empresas avaliadas somam 208,38 mil ha de área e perfazem $46 \%$ do total dos 26 programas de regularização ambiental estabelecidos em propriedades no Estado de São Paulo pelo Laboratório de Ecologia e Restauração Florestal do LCB/ESALQ/USP.

Na tabela 1 são caracterizadas as propriedades rurais objeto deste estudo, bem como são apresentadas quais propriedades foram selecionadas para aplicação dos questionários ambientais, socioeconômicos e para visitação a campo.

O PAAA do LERF/LCB/ESALQ/USP está em andamento em diversas propriedades rurais do Estado de São Paulo e, para analisá-lo em termos de quantidade de áreas, qualidade e custo da restauração, segundo orientações do Pacto pela Restauração da Mata Atlântica (2013), foi adotada a seguinte metodologia de avaliação:

A. Identificação e leitura dos projetos e relatórios de Programas de Adequação Ambiental e Agrícola realizados pelo LERF, desde 1998 até 2018, no Estado de São Paulo;

B. Avaliação dos Programas de Adequação Ambiental e Agrícola realizados pelo LERF nas propriedades rurais localizadas no Estado de São Paulo, desde 1998 até 2018, na visão dos técnicos responsáveis nestas empresas por sua execução. Essa avaliação foi desenvolvida por meio da realização de entrevistas com os atuais técnicos responsáveis pela condução de cada programa. A identificação destes técnicos foi realizada por consulta aos projetos e relatórios de cada programa elaborado pelo LERF/ESALQ/USP, com posterior entrevistas via contato telefônico ou por visitação às propriedades.

Para realizar as entrevistas de forma sistemática, foi elaborado um questionário ambiental, aplicado aos atuais gestores responsáveis pela condução de 12 programas nestas propriedades rurais. O questionário elaborado (tabela 2) traz questões que buscam inferir o grau de satisfação de cada responsável ambiental nestas propriedades sobre o respectivo PAAA em andamento. A estrutura do questionário foi baseada no questionário aplicado por Brancalion et al. (2014).

As perguntas visaram ainda a avaliar o nível de conhecimento dos atuais responsáveis ambientais sobre cada PAAA em andamento, além de quantificar o número de áreas em processo de restauração florestal, qualificar a restauração e o custo para a sua implantação.

C. De todos os PAAAs implantados pelo LERF em propriedades no Estado de São Paulo, foram autorizadas a avalição em campo das áreas em processo de restauração florestal em dez destas propriedades. A seleção das áreas visitadas em cada uma das propriedades foi por amostragem aleatória sistemática, com sorteio para instalação da parcela inicial para avaliação de campo. Cada parcela seguinte foi instalada a uma distância de $200 \mathrm{~m}$ da parcela anterior.

Visando à avaliação da qualidade da restauração foi aplicado, em cada visita de campo, o modelo de avaliação de áreas em processo de restauração ecológica, estabelecido na Resolução da Secretaria do Meio ambiente $\mathrm{n}^{\circ}$ 32, de 12 de abril de 2014 (SMA 2014).

Nessa resolução são apresentados os Valores Intermediários de Referência para o Monitoramento de Projetos de Restauração Ecológica no Estado de São Paulo (tabela 3), por tipo vegetacional e para diferentes idades. Aponte-se que esses são os critérios aceitos para aprovação ou reprovação de áreas em processo de restauração florestal pela Secretaria do Meio Ambiente do Estado de São Paulo sendo, portanto, os critérios oficiais para acompanhamento e aprovação dos PRADAs de cada propriedade.

Assim, os parâmetros medidos no campo, em cada área em processo de restauração florestal, foram: I - percentual de cobertura do solo com vegetação nativa, por projeção da copa das árvores não invasoras; II - número de espécies nativas regenerantes, por levantamentos florísticos nas áreas em restauração, dos indivíduos com altura igual ou superior a $50 \mathrm{~cm}$ e com circunferência à altura do peito menor que $15 \mathrm{~cm}$ $(\mathrm{H} \geq 50 \mathrm{~cm}$ e $\mathrm{CAP}<15 \mathrm{~cm})$; e III - densidade de indivíduos nativos regenerantes, por número de indivíduos por hectare.

Todo o material botânico coletado foi herborizado e identificado, utilizando-se bibliografia específica, consulta a especialistas e comparação com material depositado no Herbário da Escola Superior de Agricultura Luiz de Queiroz, da Universidade de São Paulo (ESA), sendo posteriormente incorporado ao Herbário ESA (acrônimo de acordo com Holmgren et al. 1990).

Esses indicadores ecológicos foram avaliados no campo, com o uso do modelo amostral proposto no Protocolo de Monitoramento de Projetos de Restauração Ecológica, da Resolução SMA 32, de 2014, que foi elaborado por diversos técnicos, com coordenação conjunta do LERF e da SMA. Dessa forma, os indicadores da resolução SMA foram 
Tabela 1. Caracterização da área de estudo das propriedades rurais participantes do Programa de Adequação Ambiental e Agrícola de Propriedades Rurais no Estado de São Paulo, Brasil.

Table 1. Characterization of the study area of rural properties participating in the Environmental and Agricultural Adequacy Program for Rural Properties in the State of São Paulo, Brazil.

\begin{tabular}{|c|c|c|c|c|c|c|}
\hline Empresa & $\begin{array}{l}\text { Município } \\
\text { / Início do } \\
\text { programa }\end{array}$ & $\begin{array}{l}\text { Número } \\
\text { total de } \\
\text { propriedades } \\
\text { por empresa }\end{array}$ & $\begin{array}{l}\text { Aplicação do } \\
\text { questionário } \\
\text { ambiental } \\
\text { (total de } \\
\text { propriedades) }\end{array}$ & $\begin{array}{c}\text { Visitação a } \\
\text { campo } \\
\text { (10 propriedades } \\
\text { sorteadas) }\end{array}$ & $\begin{array}{c}\text { Aplicação do } \\
\text { questionário } \\
\text { socioeconômico } \\
\text { (10 propriedades } \\
\text { sorteadas) } \\
\end{array}$ & $\begin{array}{l}\text { Área } \\
\text { total } \\
\text { (ha) }\end{array}$ \\
\hline $\begin{array}{c}\text { Usina da Pedra } \\
\text { S/A }\end{array}$ & Serrana - 2005 & 43 & $\mathrm{X}$ & $\mathrm{X}$ & $\mathrm{X}$ & 17.909 \\
\hline Usina São João & Araras - 1999 & 4 & $\mathrm{X}$ & $\mathrm{X}$ & $\mathrm{X}$ & 24.592 \\
\hline Usina Batatais & Batatais - 2006 & 283 & $\mathrm{X}$ & $\mathrm{X}$ & $\mathrm{X}$ & 45.015 \\
\hline Usina Lins & $\begin{array}{l}\text { Lins - } \\
2010\end{array}$ & 266 & $\mathrm{X}$ & $\mathrm{X}$ & $\mathrm{X}$ & 26.845 \\
\hline $\begin{array}{c}\text { Estação } \\
\text { Experimental } \\
\text { Anhembi }\end{array}$ & Anhembi - 2007 & 4 & $\mathrm{X}$ & $\mathrm{X}$ & $\mathrm{X}$ & 500 \\
\hline Usina Colombo & Ariranha - 2010 & 217 & $\mathrm{X}$ & $\mathrm{X}$ & $\mathrm{X}$ & 24.437 \\
\hline $\begin{array}{c}\text { Usina Branco } \\
\text { Peres }\end{array}$ & $\begin{array}{l}\text { Adamantina - } \\
2008\end{array}$ & 34 & $\mathrm{X}$ & $\mathrm{X}$ & $\mathrm{X}$ & 6.944 \\
\hline Usina Ipê & $\begin{array}{c}\text { Nova } \\
\text { Independência - } \\
2006\end{array}$ & 12 & $\mathrm{X}$ & - & $\mathrm{X}$ & 7.150 \\
\hline Usina Moema & $\begin{array}{l}\text { Orindiúva - } \\
2010\end{array}$ & 32 & $\mathrm{X}$ & $\mathrm{X}$ & $\mathrm{X}$ & 16.870 \\
\hline Usina São Manoel & $\begin{array}{l}\text { São Manoel - } \\
2005\end{array}$ & 124 & $\mathrm{X}$ & - & $\mathrm{X}$ & 38.061 \\
\hline $\begin{array}{c}\text { Estação } \\
\text { Experimental - } \\
\text { BASF }\end{array}$ & $\begin{array}{l}\text { Santo Antônio } \\
\text { de Posse - } 2006\end{array}$ & 1 & $\mathrm{X}$ & $\mathrm{X}$ & - & 36,35 \\
\hline $\begin{array}{c}\text { Sítio Alvorada - } \\
\text { BASF }\end{array}$ & Amparo - 2008 & 1 & $\mathrm{X}$ & $\mathrm{X}$ & - & 22,43 \\
\hline Total & - & 1.021 & 12 & 10 & 10 & 208.38 \\
\hline
\end{tabular}

avaliados em parcelas amostrais de $100 \mathrm{~m}^{2}(4 \mathrm{~m} \times 25 \mathrm{~m})$, distribuídas de forma aleatória nas áreas em processo de restauração florestal (figura 1).

O número de parcelas instaladas por área sorteada foi definido conforme a metodologia proposta no Pacto pela Restauração da Mata Atlântica (2013). Isto é, cinco parcelas em áreas entre 0,5 e 1ha, e, nas áreas maiores que 1ha, a instalação de uma parcela adicional a cada 1 ha de área. Neste trabalho, em função do grande número de áreas a serem amostradas, o número máximo de parcelas instaladas por área foi dez, ao invés das 50 propostas na metodologia seguida (tabela 4 ).

Para a avaliação dos benefícios diretos e indiretos do Programa de Adequação Ambiental e Agrícola, em termos socioeconômicos, utilizou-se a entrevista semiestruturada, conforme recomendações de Haguette (2001). Partiu-se de um roteiro elaborado no formato de questionário, visando a extrair o máximo de informações das entrevistas e assegurar coerência para auxiliar na condução da conversação. O presente questionário foi elaborado com a finalidade de identificar os possíveis ganhos socioeconômicos obtidos com a adesão ao PAAA junto a estas propriedades rurais.

Com base no conjunto de propriedades atendidas pelo PAAA do LERF, desde 1998, no Estado de São Paulo, dez gestores ambientais aceitaram responder a um segundo questionário, visando avaliar os possíveis benefícios socioeconômicos obtidos com a inserção deste programa em cada propriedade (tabela 5).

Conforme explicitado no Termo de Consentimento Livre e Esclarecido (TCLE), aprovado no parecer do Comitê de Ética em Pesquisa $n^{\circ}$. 2.145.237 da ESALQ-USP, não foi divulgado o nome de cada empresa vinculado às respostas dadas a esses questionários. Além da entrevista semiestruturada, com o uso de questionários de avaliação dos resultados ambientais e socioeconômicos dos PAAAs, 
Tabela 2. Questionário elaborado para a avaliação dos resultados ambientais do Programa de Adequação Ambiental e Agrícola de Propriedades Rurais do LERF/LCB/ESALQ/USP.

Table 2. Questionnaire designed to assess the environmental results of the Environmental and Agricultural Adequacy Program for Rural Properties of LERF/LCB/ESALQ/USP.

Questionário - Avaliação dos resultados socioeconômicos do PAAA

Nome: Empresa: Município: Telefone / E-mail:

1) Qual o nome do responsável pela área ambiental da empresa?

2) O Programa de Adequação Ambiental e Agrícola teve início em que ano na empresa?

3) Qual o total de hectares que receberam ações de restauração florestal até hoje no PAAA?

4) Desse total de hectares, quantos correspondem às áreas em processo de restauração em APP (Área de Preservação Permanente) e fora de APP (em Reserva Legal)?

5) Qual o número de mudas plantadas nas áreas em processo de restauração florestal até hoje?

6) A empresa implantou e mantém viveiro de mudas de espécies nativas?

7) Se a empresa implantou e mantém tal viveiro, qual o número de mudas produzidas por ano para o PAAA?

8) Qual o número de trabalhadores envolvidos com a atividade de restauração florestal na empresa para o cumprimento do PAAA?

9) Qual o custo anual aproximado para o cumprimento do programa de restauração florestal na empresa?

10) As áreas não agrícolas são protegidas (aceiros, cercas, etc) para a prevenção de possíveis fatores de degradação?

11) Se as áreas agrícolas são protegidas, com qual (is) estratégia (s) de isolamento?

12) A empresa usa aplicação aérea de herbicida/inseticida ou hormônios maturadores nas áreas agrícolas?

13) Se a empresa usa aplicação aérea de herbicida/inseticida ou hormônios maturadores, qual (is) é/são utilizado (s)?

14) A empresa adota práticas de conservação de solo nas áreas agrícolas, de modo a dificultar o escoamento superficial de solo, de água e de pesticidas para as áreas não agrícolas?

15) Se a empresa adota práticas de conservação de solo nas áreas agrícolas, qual (is) técnica (s) é/são adotada (s)?

16) Existe na empresa uma brigada de incêndio à disposição?

17) Qual a sua avaliação qualitativa das áreas que estão em processo de restauração na empresa?

( ) Excelente ( ) Boa ( ) Regular ( ) Ruim

18) Você acredita que essas áreas que receberam ações de restauração florestal seriam aprovadas pelo órgão ambiental responsável (Secretária do Meio Ambiente - SP)?

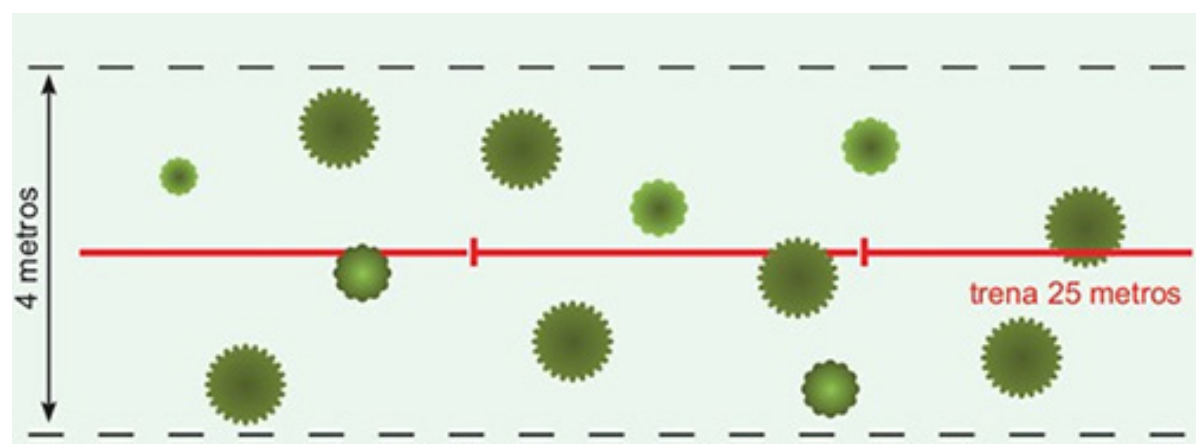

Figura 1. Vista superior de uma unidade amostral ilustrando o formato de parcela retangular para o monitoramento da restauração florestal (Pacto pela Restauração da Mata Atlântica, 2013).

Figure 1. Upper view of a sampling unit illustrating the shape of a rectangular plot for monitoring forest restoration (Pact for the Restoration of the Atlantic Forest, 2013). 
Tabela 3. Valores Intermediários de Referência para o Monitoramento de Projetos de Restauração Ecológica no Estado de São Paulo no bioma Mata Atlântica (modificado da Resolução no ${ }^{0}$ 2, da SMA 2014), Brasil. Crítico: não foram atingidos os valores mínimos esperados no prazo determinado e será exigida a readequação do projeto por meio de ações corretivas; Mínimo: os valores estão dentro da margem de tolerância para o prazo determinado e cumprem as exigências mínimas, porém os valores são inferiores ao esperado, o que indica a necessidade de realização de ações corretivas para não comprometer os resultados futuros; Adequado: foram atingidos os valores esperados para o prazo determinado.

Table 3. Intermediate Reference Values for Monitoring Ecological Restoration Projects in the State of São Paulo in the Atlantic Forest biome (modified from SMA Resolution $n^{\circ} 32,2014$ ), Brazil. Critical: not reached the minimum values expected within the determined period and the readjustment of the project will be required using corrective actions; Minimum: the values are within the tolerance margin for the determined period and meet the minimum requirements, however, the values are lower than expected, which indicates the need to take corrective actions so as not to compromise future results; Adequate: the expected values for the specified period has been reached.

\begin{tabular}{|c|c|c|c|c|c|c|c|c|c|}
\hline \multicolumn{10}{|c|}{$\begin{array}{c}\text { Valores Intermediários de Referência para o Monitoramento de Projetos } \\
\text { de Restauração Ecológica no Estado de São Paulo. }\end{array}$} \\
\hline Indicador & \multicolumn{3}{|c|}{$\begin{array}{l}\text { Cobertura do solo com } \\
\text { Vegetação nativa (\%) }\end{array}$} & \multicolumn{3}{|c|}{$\begin{array}{l}\text { Densidade de indivíduos nativos } \\
\text { regenerantes }(\%)\end{array}$} & \multicolumn{3}{|c|}{$\begin{array}{l}\mathrm{N}^{\circ} \text {. de espécies nativas } \\
\text { regenerantes }\end{array}$} \\
\hline $\begin{array}{l}\text { Nível de } \\
\text { Adequação }\end{array}$ & crítico & mínimo & adequado & crítico & mínimo & adequado & crítico & mínimo & adequado \\
\hline 3 anos & 0 a 15 & 15 a 80 & $\begin{array}{l}\text { acima de } \\
\quad 80\end{array}$ & - & 0 a 200 & $\begin{array}{l}\text { acima de } \\
200\end{array}$ & - & 0 a 3 & $\begin{array}{c}\text { acima } \\
\text { de } 3\end{array}$ \\
\hline 5 anos & 0 a 30 & 30 a 80 & $\begin{array}{l}\text { acima de } \\
\quad 80\end{array}$ & 0 a 200 & $\begin{array}{c}200 \mathrm{a} \\
1000\end{array}$ & $\begin{array}{l}\text { Acima de } \\
1000\end{array}$ & 0 a 3 & 3 a 10 & $\begin{array}{l}\text { acima de } \\
10\end{array}$ \\
\hline 10 anos & 0 a 50 & 50 a 80 & $\begin{array}{l}\text { acima de } \\
\quad 80\end{array}$ & 0 a 1000 & $\begin{array}{c}1000 \mathrm{a} \\
2000\end{array}$ & $\begin{array}{l}\text { Acima de } \\
2000\end{array}$ & 0 a 10 & 10 a 20 & $\begin{array}{l}\text { acima de } \\
20\end{array}$ \\
\hline 15 anos & 0 a 70 & 70 a 80 & $\begin{array}{l}\text { acima de } \\
\quad 80\end{array}$ & 0 a 2000 & $\begin{array}{c}2000 \mathrm{a} \\
2500\end{array}$ & $\begin{array}{l}\text { Acima de } \\
2500\end{array}$ & 0 a 20 & 20 a 25 & $\begin{array}{l}\text { acima de } \\
25\end{array}$ \\
\hline
\end{tabular}

Tabela 4. Delimitação do número de parcelas amostrais (adaptado do Pacto pela Restauração da Mata Atlântica, 2013).

Table 4. Delimitation of the number of sample plots (adapted from the Pact for the Restoration of the Atlantic Forest, 2013).

\begin{tabular}{cc}
\hline Área do Projeto $(\mathrm{ha})=\mathrm{A}$ & $\mathrm{N}^{\mathrm{o}}$ de parcelas amostrais \\
\hline $\mathrm{A} \leq 0,5$ & Desprezar o projeto para fins de monitoramento \\
$0,5<\mathrm{A} \leq 1$ & 5 \\
$\mathrm{~A}>1$ & $5+(1$ por hectare adicional $) *$ \\
\hline
\end{tabular}

- limitado a um número máximo de 10 parcelas, independente da área do projeto.

foram também adotados dois procedimentos complementares para fins de investigação científica: a observação participante e a análise documental.

Conforme as orientações de Haguette (2001), adotou-se a observação participante, procedimento no qual o pesquisador permaneceu junto ao entrevistado no momento em que os questionários foram aplicados, quando realizadas as entrevistas durante a visitação a estas propriedades. No caso desse trabalho, os entrevistados foram os técnicos responsáveis pela condução de cada PAAA nas propriedades rurais.

Ainda, conforme as recomendações de Cechinel et al. (2016), foi aplicada a análise documental como procedimento, que consistiu no levantamento, na análise e na extração de informações de documentos como projetos, registros e relatórios sobre o PAAA de cada propriedade.

Análise dos Dados - Para a análise do conjunto de dados obtidos, foram adotadas as seguintes etapas:

A. Análise dos questionários de avaliação ambiental e socioeconômica: as respostas obtidas nos questionários ambientais e socioeconômicos em cada empresa foram agrupadas para a interpretação total dos dados disponibilizados.

As informações resultantes desses questionários foram analisadas conforme as recomendações de Haguette (2001). 
Tabela 5. Questionário elaborado para avaliação dos resultados socioeconômicos do Programa de Adequação Ambiental e Agrícola (PAAA) de propriedades rurais do LERF/LCB/ESALQ/USP.

Table 5. Questionnaire designed to assess the socioeconomic results of the Environmental and Agricultural Adequacy Program (PAAA) for rural properties areas of LERF/LCB/ESALQ/USP.

Questionário - Avaliação dos resultados socioeconômicos do PAAA

Nome: _ Empresa: _ Município: _ Telefone / E-mail:

1) Qual o número de funcionários totais envolvidos no cumprimento do Programa de Adequação Ambiental e Agrícola de Propriedades Rurais (PAAA)?

2) Qual o salário médio dos funcionários envolvidos com o cumprimento do PAAA?

3) Das mudas produzidas neste programa, foram doadas mudas às propriedades fora do PAAA?

( ) $\operatorname{sim}$ ( ) não

4) Caso tenha havido doação, quantas mudas foram doadas para essas propriedades fora do PAAA?

5) Os funcionários envolvidos recebem treinamento periódico para assegurar a execução do Programa de Adequação Ambiental e Agrícola?

( ) $\operatorname{sim}($ ) não

6) Em caso dos funcionários envolvidos terem recebido treinamento, com que regularidade?

7) A empresa desenvolve atividades de Educação Ambiental com seus funcionários?

( ) $\operatorname{sim}$ ( ) não

8) Se a empresa desenvolve atividades de Educação Ambiental (palestras, trilhas educativas de espécies nativas, etc), quais tipos de atividades e temas são desenvolvidos?

9) O PAAA foi usado para certificação ambiental da área Agrícola?

10) Se o PAAA foi usado para certificação ambiental, com qual (is) certificadora (s)?

Isto é, por meio do agrupamento dos métodos qualitativo e quantitativo na interpretação dos dados e na constituição das informações, com a sistematização e avaliação conjunta das respostas disponibilizadas nos questionários.

Os dados documentais complementares foram disponibilizados pelos atuais profissionais responsáveis pelos PAAAs em cada propriedade rural, permitindo o levantamento dos possíveis benefícios ambientais e socioeconômicos obtidos com o cumprimento do programa nessas propriedades rurais (Cechinel et al. 2016).

$\mathrm{Na}$ análise dos questionários ambientais foram quantificados os números totais de hectares que receberam ações de restauração florestal, de mudas plantadas nos projetos de restauração e do custo para o seu cumprimento, bem como de outros dados do programa que resultaram em possíveis benefícios ao meio ambiente. Após a análise das respostas, foi realizada a checagem dos ganhos ambientais obtidos com a implantação desse programa nas propriedades rurais.

$\mathrm{Na}$ análise dos questionários com os resultados socioeconômicos, foram avaliados os possíveis benefícios obtidos com o cumprimento do PAAA. Quantificouse, então, o número de trabalhadores envolvidos com o cumprimento do programa, sua renda média, a obtenção de certificação ambiental com a regularização ambiental destas propriedades, a implantação de trilhas educativas e programas de educação ambiental, entre outros ganhos socioeconômicos. Todos esses dados são indicadores favoráveis para a consolidação e para o sucesso das iniciativas de restauração florestal (Brancalion et al. 2015).

B. Análise dos resultados da avaliação em campo das áreas em processo de restauração florestal: avaliação de dez propriedades sorteadas de acordo com os parâmetros estabelecidos pela Resolução SMA 32 (2014). A classificação dos indicadores de monitoramento avaliados em campo (percentual de cobertura do solo com vegetação nativa, número de indivíduos e de espécies nativas regenerantes), em nível adequado, mínimo ou crítico, permitiu qualificar as áreas em processo de restauração florestal, de modo a verificar se essas áreas estão dentro dos valores de referência estabelecidos pelo órgão de fiscalização desses projetos, a Secretaria do Meio Ambiente do Estado de São Paulo, conforme suas respectivas idades.

Com base nos resultados da avaliação dos PAAAs, foram propostas possíveis ações corretivas em sua condução, visando a potencializar o papel de conservação e restauração da diversidade vegetal remanescente destas propriedades. Aponte-se que as recomendações englobaram tanto o âmbito individual, havendo orientações específicas e próprias para cada propriedade, quanto o geral, havendo recomendações de melhorias do programa como um todo. 


\section{Resultados e discussão}

Análise da realidade de campo na avaliação dos responsáveis pela execução do Programa de Adequação Ambiental e Agrícola de Propriedades Rurais - Em relação aos questionários ambientais, foram respondidos e analisados um total de 12 questionários, referentes ao levantamento dos possíveis ganhos ambientais advindos da inserção do PAAA nas propriedades avaliadas.

Os PAAAs implantados nessas propriedades rurais têm idades entre oito e 19 anos, o que demonstra um tempo razoável para o monitoramento destas áreas em processo de restauração florestal, pois, de acordo com a Resolução SMA 32 (2014), o tempo mínimo recomendado para esse tipo de análise é três anos. Deste modo, temos aqui áreas com pelo menos cerca de três vezes mais do que o tempo mínimo recomendado.

Deste total de 2.843 ha de áreas em processo de recuperação florestal, 2.563 ha referem-se à restauração em APPs, ou seja, 90,15\% do total, enquanto $280 \mathrm{ha}$ correspondem às áreas de RL, ou seja, 9,85\% do total. Recomenda-se aqui, portanto, nas propriedades rurais que atualmente estão com sua área de RL inferior ao percentual mínimo de $20 \%$ exigido pela LPVN, que os responsáveis ambientais por estas áreas atuem nestas propriedades com a delimitação da área adequada exigida para RL, com a recomposição da cobertura florestal nativa.

Cabe ressaltar que, atualmente, é admitido o cômputo das APPs no cálculo do percentual da RL do imóvel, desde que não implique na conversão de novas áreas para o uso alternativo do solo (Brasil 2012). Assim, estes proprietários podem inclusive computar as APPs neste percentual necessário para adequação de sua RL conforme exigido pela LPVN.

Ainda, até a publicação da LPVN (Lei Federal ${ }^{\circ} 12.651$, de 2012), 130ha, do total de 280 ha que atualmente estão em área de RL nesses PAAAs, estavam situados em área de APP. Em virtude da diminuição da largura das margens dos cursos d'água que devem ser consideradas como APPs, nos termos do artigo $4^{\circ}$ da LPVN, as áreas que anteriormente estavam situadas em APP foram incorporadas à RL por estes proprietários, que afirmaram ter ciência do papel destas áreas para a proteção dos cursos d'água, da biodiversidade regional e manutenção da estabilidade geológica do solo no ambiente ciliar. Tal fenômeno resultou em uma diminuição das áreas localizadas em APP com cobertura vegetal nativa.

Com esse propósito, nos PAAAs das propriedades com necessidade de recomposição das APPs com plantio total, em função do elevado nível de degradação daquela situação, o programa recomendou o plantio de espécies nativas regionais próprias de cada ecossistema, além da adoção de práticas adequadas de conservação do solo, incluindo a construção de estradas e carreadores em local apropriado (Falkenmark et al. 2014). Essas medidas de proteção dos cursos d'água e nascentes contribuem com a manutenção da vazão dos rios, proporcionando o fornecimento dos serviços ecossistêmicos dependentes desses recursos hídricos (Honda \& Durigan 2017).

Em relação à produção anual média de mudas de espécies nativas nessas propriedades rurais inseridas no PAAA, foi observada uma variação entre 60,000 a 300,000 mudas produzidas anualmente nos sete viveiros existentes nas propriedades que aderiram ao programa, essa variação obedeceu à demanda de cada projeto e, dado o método científico empregado, foram estabelecidas as particularidades de cada situação, quanto ao potencial de recuperação de cada área em questão, ao uso e ocupação, pretérita, atual e futura, ao potencial de regeneração natural e ao déficit de Reserva Legal existente.

Em síntese, o PAAA possibilitou, nesses 20 anos de existência (1998 a 2018), um plantio total de 6,33 milhões de mudas nessas propriedades.

O cumprimento do PAAA nessas empresas contou com a participação de 106 trabalhadores diretos, ou seja, que estiveram envolvidos com as atividades de restauração florestal. O custo de implantação dos PAAAs variou entre $\mathrm{R} \$ 500.000,00$ a $\mathrm{R} \$ 1.000 .000,00$, essa variação de custo de restauração está diretamente relacionada às diferenças existentes entre os tamanhos das áreas em processo de restauração florestal em cada empresa, bem como aos objetivos e às demandas de cada projeto.

Essas medidas favorecem as condições do ambiente para a reocupação por espécies nativas nessas áreas, potencializando, assim, a condução da regeneração natural (Rother et al. 2018). O isolamento adequado das áreas em processo de recuperação ambiental dos fatores de degradação permite acelerar o processo de restauração florestal (Rozza et al. 2006).

Vale ressaltar que as primeiras intervenções para o favorecimento dos indivíduos regenerantes, tais como a construção de aceiros, implantação de cercas e controle de espécies invasoras, já podem ser capazes de desencadear o processo de sucessão e permitir a ocupação progressiva de uma área em processo de restauração florestal por espécies nativas regenerantes (Isernhagen et al. 2009), nos casos de restauração de áreas não muito degradadas, com alguma resiliência (Rodrigues et al. 2017).

Excetuando-se uma das empresas, as outras nove estão situadas em áreas cuja atividade agrícola é altamente tecnificada. Na maioria o cultivo é de cana-de-açúcar, onde foram aplicados herbicidas pré e pós-emergentes, e outros produtos como os fungicidas (e.g. Opera e/ou Priori xtra), inseticidas (e.g. Actara $750 \mathrm{SG}$, Altacor WG e/ou Certero SC 480), óleo mineral (e.g. Oppa), além de maturadores (e.g. Moddus e Curavial), que reduziram muito qualquer possibilidade de expressão da regeneração natural, definindo-se como metodologia de restauração nessas áreas o plantio total de mudas e/ou sementes.

As dez empresas analisadas adotaram práticas de conservação de solo nas áreas em restauração e nas áreas agrícolas do entorno, por meio de terraços e plantio em 
nível, de modo a dificultar o escoamento superficial do solo e, com isso, reduzir os processos erosivos (Maria \& Peche-Filho 2009). Além disso, o cultivo mínimo também é utilizado nas áreas agrícolas por uma das empresas, prática essa que não envolve o revolvimento do solo em área total, adequando-se às condições de declividade e de escoamento da água pluvial (Gonçalves 2009).

Todas as empresas têm à disposição uma brigada de incêndio, para evitar fogo nas áreas em restauração, sendo que em uma destas empresas essa brigada foi constituída pelos próprios funcionários responsáveis pelo PAAA.

A adoção de práticas de conservação do solo era uma das recomendações iniciais dos PAAAs. Entre estas práticas, destacam-se a construção de terraços, o cultivo mínimo e a readequação da drenagem superficial, medida que visa a reduzir os processos erosivos, o acúmulo de sedimentos e o arraste de sementes e plântulas pela enxurrada (Brancalion et al. 2015).

Foi solicitado aos gestores ambientais que realizassem uma avaliação qualitativa das áreas das propriedades em processo de recuperação florestal (tabela 6).

De acordo com essa análise, realizada pelos técnicos responsáveis pela condução de cada programa, no mínimo $70 \%$ das áreas foram avaliadas como boas ou excelentes quanto ao seu processo de recuperação florestal.

Esse resultado foi reiterado pelas respostas dadas à última questão do questionário, na qual todos os gestores ambientais afirmaram acreditar que, se o total das áreas em processo de restauração fosse avaliado em cada empresa, haveria a aprovação pela Secretaria do Meio Ambiente do Estado de São Paulo (SMA-SP) de sua situação atual de recomposição da diversidade vegetal.

Devido à limitação legal do uso dessas áreas para atividades agropecuárias, a maior parte das ações de restauração florestal está concentrada em áreas de APP e RL (Pinto et al. 2014). No entanto, nada impede que essas atuações restaurativas excedam os limites mínimos de modo a, por exemplo, incluir as áreas de baixa aptidão agrícola e definir a condução da restauração florestal para além das obrigações legais da propriedade rural (Vidal et al. 2014, Brancalion et al. 2015).
As ações de recuperação florestal estabelecidas foram também avaliadas em campo, visando complementar os resultados do levantamento realizado com os questionários dos possíveis ganhos ambientais trazidos com a inserção do Programa de Adequação Ambiental nestas propriedades.

Avaliação da efetividade das ações de restauração florestal estabelecidas em campo pelo Programa de Adequação Ambiental e Agrícola de Propriedades Rurais - A lista de espécies botânicas, traqueófitas, amostradas em campo durante o monitoramento das áreas sorteadas com plantio florestal (tabela 7) evidencia a necessidade de algumas ações corretivas no PAAA de cada propriedade avaliada, tais como a retirada das espécies exóticas invasoras encontradas nestas áreas (Leucaena leucocephala (Lam.) de Wit, Mangifera indica L. e Tecoma stans (L.) Juss. ex Kunth.).

Em ecossistemas degradados, frequentemente espécies exóticas se beneficiam do ambiente alterado e inibem a regeneração natural de espécies nativas (Isernhagen et al. 2009). Nesse cenário, as espécies exóticas invasoras podem alterar funções no ecossistema, competindo com espécies nativas por recursos (e.g. fornecimento de água, exposição à luz, disponibilidade de nutrientes do solo, etc.) e interferir na sucessão secundária ao ocupar os nichos anteriormente habitados por espécies nativas (Mangueira et al. 2019).

Em alguns casos, a presença de espécies exóticas com comportamento não invasor não representa uma ameaça ao equilíbrio do ecossistema, e em áreas degradadas ou em processo de restauração florestal é possível até utilizá-las como aliadas na recuperação do ecossistema (D'Antônio \& Meyerson 2002). A utilização de espécies exóticas para adubação verde (e.g. Crotalaria ochroleuca G. Don, Sesamum indicum L., Cajanus cajan (L.) Huth e Crotalaria juncea L.) é recomendada, já que essas espécies atuam como pioneiras na reocupação de ecossistemas degradados (Nave et al. 2009, Brancalion et al. 2015).

Não obstante, quando as espécies exóticas têm comportamento invasor, como as supracitadas que foram identificadas durante o monitoramento das áreas com plantio de restauração, estas podem dominar a comunidade ou interferir de forma negativa na sucessão do ecossistema.

Tabela 6. Avaliação qualitativa dos gestores ambientais quanto ao estado de conservação das áreas em processo de recuperação florestal.

Table 6. Qualitative assessment of environmental managers regarding the conservation status of areas undergoing recovery forestry.

Estado de conservação das áreas em processo de recuperação florestal

Porcentagem na avaliação dos gestores ambientais (\%)

$\begin{array}{cc}\text { Ruim } & 0 \text { a } 10 \\ \text { Regular } & 20 \text { a } 30 \\ \text { Bom } & 40 \text { a } 70 \\ \text { Excelente } & 10 \text { a } 30\end{array}$


Nesses casos, é necessária a adoção de ações de controle e manejo dessas espécies, de forma a auxiliar a recuperação florestal (Nave et al. 2009).

Recomenda-se, assim, a retirada destas espécies exóticas invasoras, tomando-se o cuidado de se concentrar o impacto de sua queda sobre a entrelinha que está sendo retirada, o que pode ser feito com o uso de motosserra ou de machado (Lamonato et al. 2016). A madeira deve ser retirada da área e pode, inclusive, ser comercializada.

Neste contexto, sugere-se a comercialização de produtos florestais madeireiros e não madeireiros advindos das espécies florestais destas propriedades, além da adoção de outras estratégias metodológicas que possibilitem conciliar a produção agrícola à conservação da biodiversidade, que são interdependentes (Vidal et al. 2016, Amazonas et al. 2018).

Cabe ressaltar a importância da comercialização de produtos florestais madeireiros e não madeireiros, entre eles, a produção de mel, extratos, folhas, frutos e a retirada de espécies exóticas com valor comercial das áreas em processo de recuperação ambiental destas propriedades (Brancalion et al. 2015, Amazonas et al. 2018).

O rendimento da restauração florestal com fins econômicos em geral é bem maior quando comparado ao rendimento da pecuária extensiva (Brancalion et al. 2012, Latawiec et al. 2015). Como exemplos, pode ser citada a readequação do uso do solo nas Fazendas Guariroba (Campinas, SP) e Capoava (Itu, SP) (Rodrigues et al. 2016). A geração de recursos financeiros com a comercialização de produtos florestais promove, consequentemente, a redução nos custos dos programas de restauração, gerando trabalho e renda aos envolvidos com as ações de restauração florestal (Latawiec et al. 2015).

Paralelamente, é recomendado o controle químico da rebrota das espécies exóticas invasoras, por meio da aplicação de herbicida autorizado, do tipo glifosato nas cepas, devendo ser pincelado o herbicida puro sobre a região do floema (Nave et al. 2009).

Os resultados desses indicadores ecológicos (tabela 8) evidenciaram a necessidade de ações de adensamento, por meio do aumento no número de indivíduos em áreas onde a regeneração natural é baixa ou espacialmente heterogênea (Brancalion et al. 2012), associadas à condução da regeneração natural nas empresas Usina da Pedra S/A, Usina São João, Usina Branco Peres, Estação Experimental Anhembi, Estação Experimental de Santo Antônio de Posse e Sítio Alvorada.

As Usinas Batatais, Lins e Colombo apresentaram valores adequados para os três indicadores ecológicos avaliados. Esse resultado indica a necessidade somente da manutenção do isolamento dos fatores de degradação presentes nessas áreas, tais como a eventual ocorrência de lianas em desequilíbrio, gramíneas e espécies exóticas invasoras.

É importante ressaltar ainda que o monitoramento periódico das áreas em processo de restauração florestal é essencial mesmo quando essas apresentam valores adequados em relação aos indicadores ecológicos. Tal necessidade se dá pelo histórico de uso e pela dinâmica de perturbação desses locais, pois há alta suscetibilidade destes remanescentes florestais à recorrente incidência de fatores de degradação (e.g. lianas em desequilíbrio, gramíneas exóticas, além de outras espécies invasoras), visto que a cobertura florestal nativa remanescente nestas áreas está situada próxima a áreas de cultivos agrícolas (Viani et al. 2017).

Para fins ilustrativos da importância do acompanhamento da situação das propriedades ao longo dos anos, incluise neste trabalho algumas imagens aéreas da Estação Experimental Agrícola da BASF, localizada no município de Santo Antônio de Posse - SP. Na figura 2, é possível visualizar a Estação Experimental da BASF localizada no município de Santo Antônio de Posse - SP, no ano de 2008, período anterior ao início do processo de restauração florestal.

A figura 3 ilustra a cobertura vegetal florestal desta mesma área da Estação Experimental Agrícola da BASF, no ano de 2018, período correspondente a inserção do Programa de Adequação Ambiental e Agrícola. Verificase nesta imagem mais recente da área uma cobertura de vegetação densa, correspondente hoje a um plantio de adensamento com espécies de recobrimento realizado na área pelo Programa de Adequação Ambiental e Agrícola.

Adicionalmente, na figura 4 é apresentado o mapa de uso e ocupação atual do solo em uma das áreas da Estação Experimental da BASF, com suas delimitações, tais como os limites da propriedade, APP, nascentes, áreas de uso rural e demais características presentes.

Em síntese, averiguou-se, nesta avaliação, que os dados obtidos no questionário ambiental, referente à avaliação qualitativa dos técnicos responsáveis de cada programa nas áreas das propriedades em processo de recuperação florestal, são condizentes aos valores obtidos na avaliação dos indicadores ecológicos de monitoramento avaliados em campo, visto que três propriedades rurais apresentaram valores adequados em relação a todos os indicadores ecológicos de monitoramento de restauração florestal avaliados ( $30 \%$ excelente), conforme previsto no cronograma de adequação ambiental e agrícola da Resolução n. 32, da SMA (2014).

Ainda, outras seis propriedades detêm valores adequados para dois destes indicadores ecológicos avaliados ( $60 \%$ bom a regular), no caso, percentual de cobertura do solo com vegetação nativa e número de espécies nativas regenerantes (quatro propriedades), densidade de indivíduos nativos regenerantes e número de espécies nativas regenerantes (uma propriedade) e percentual de cobertura do solo com vegetação nativa e densidade de indivíduos nativos regenerantes (uma propriedade).

Por sua vez, somente uma destas propriedades apresentou valor inadequado para somente um indicador ecológico $(10 \%$ ruim), no caso, número de espécies nativas regenerantes.

Estes dados da avaliação em campo e as propostas para adequação ambiental e agrícola destas propriedades 


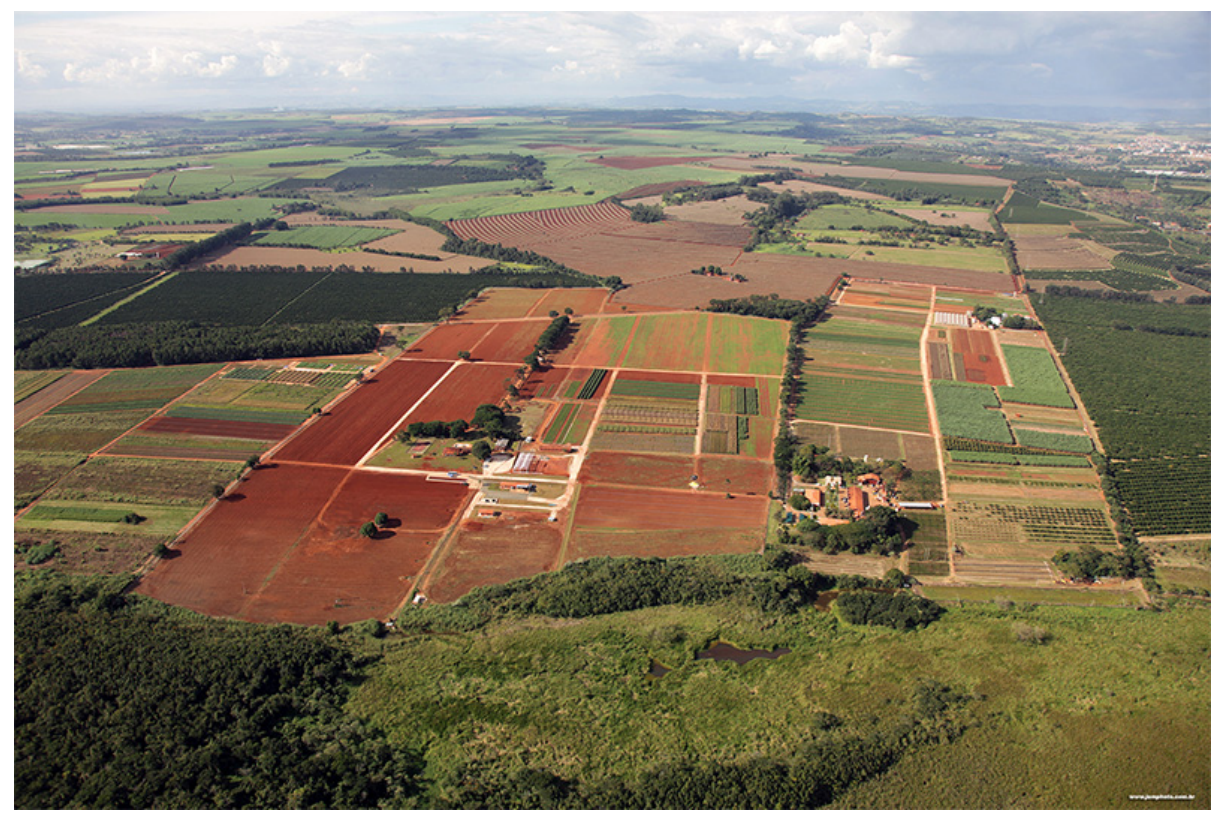

Figura 2. Imagem aérea da Estação Experimental da BASF, localizada em Santo Antônio de Posse, SP, Brasil, antes da restauração ser iniciada em 2008. Imagem disponibilizada por Tiago Egydio Barreto.

Figure 2. Aerial image of the BASF Experimental Station, located in Santo Antônio de Posse, SP, Brazil, before the restoration is started in 2008. Image provided by Tiago Egydio Barreto.

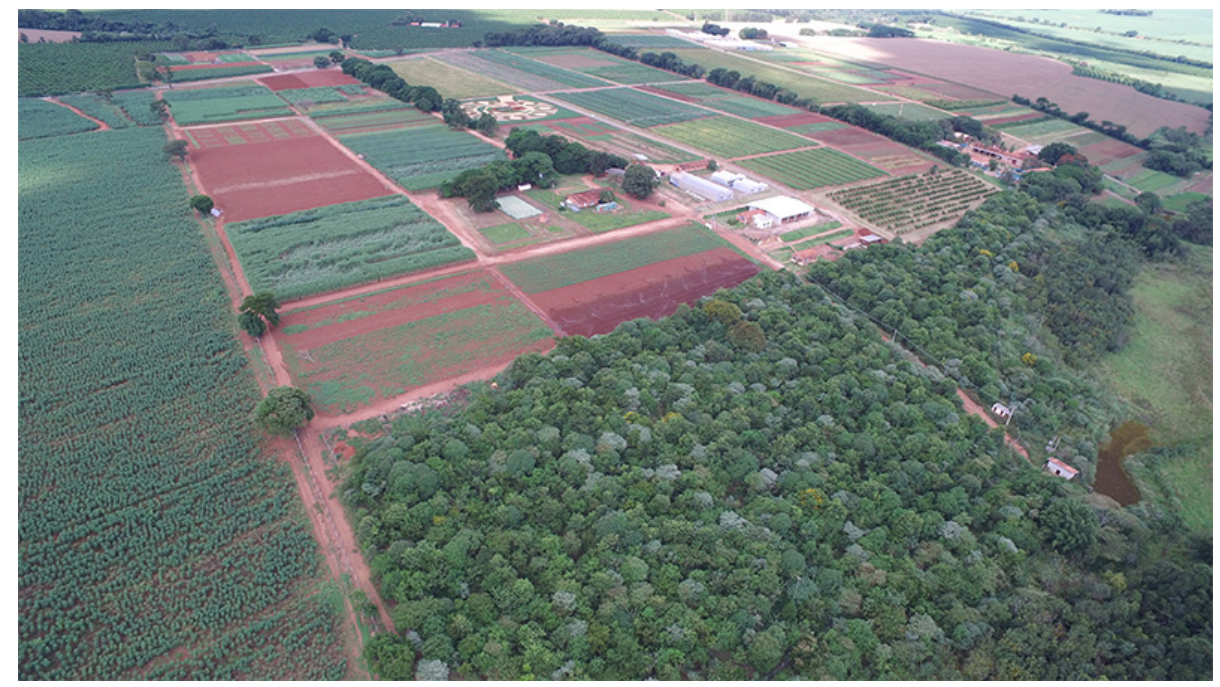

Figura 3. Imagem aérea da Estação Experimental da BASF, localizada em Santo Antônio de Posse, SP, Brasil, em 2018. Imagem disponibilizada por Tiago Egydio Barreto.

Figure 3. Aerial image of the BASF Experimental Station, located in Santo Antônio de Posse, SP, Brazil, in 2018. Image provided by Tiago Egydio Barreto.

embasadas nestes resultados, ressaltam que as ações de restauração florestal estabelecidas pelo PAAA nestas propriedades estão tendo êxito em termos de efetividade ambiental da qualidade de áreas em processo de restauração florestal. Evidenciando-se ainda que, seguindo-se as recomendações propostas para o manejo adaptativo adequado das áreas que apresentaram valores mínimos em relação aos indicadores ecológicos avaliados, será possível a correção das não adequações detectadas, contribuindo assim para o sucesso do Programa de Adequação Ambiental e Agrícola de Propriedades Rurais e a regularização ambiental e agrícola destas propriedades. 
Tabela 7. Lista de espécies botânicas, traqueófitas e número de indivíduos por espécie amostrados no monitoramento das áreas com plantio de restauração visitadas nas propriedades atendidas pelo PAAA. P1: Usina da Pedra S/A; P2: Usina São João; P3: Usina Batatais; P4: Usina Lins; P5: Estação Experimental Anhembi; P6: Usina Colombo; P7: Usina Branco Peres; P8: Usina Moema; P9: Estação Experimental de Santo Antônio de Posse; P10: Sítio Alvorada.

Table 7. List of botanical tracheophyte species and number of individuals per species sampled in the monitoring of areas with restoration plantations visited in the properties served by the PAAA. P1: Usina da Pedra S/A; P2: Usina São João; P3: Usina Batatais; P4: Usina Lins; P5: Estação Experimental Anhembi; P6: Usina Colombo; P7: Usina Branco Peres; P8: Usina Moema; P9: Estação Experimental de Santo Antônio de Posse; P10: Sítio Alvorada.

\begin{tabular}{|c|c|c|c|c|c|c|c|c|c|c|}
\hline Família/Espécie & $\mathrm{P} 1$ & $\mathrm{P} 2$ & P3 & $\mathrm{P} 4$ & P5 & P6 & P7 & P8 & P9 & P10 \\
\hline \multicolumn{11}{|l|}{ Anarcadiaceae } \\
\hline Astronium graveolens Jacq. & - & - & - & - & 6 & - & - & - & - & - \\
\hline Mangifera indica $\mathrm{L}$. & - & 3 & - & - & - & 2 & - & - & - & - \\
\hline Myracrodruon urundeuva Allemão & 1 & - & - & - & 1 & - & - & 1 & - & - \\
\hline Schinus terebinthifolia Raddi & - & 1 & 5 & 22 & - & 5 & 13 & - & 3 & - \\
\hline Tapirira guianensis Aubl. & 9 & 1 & 15 & 7 & - & 5 & - & - & 26 & 1 \\
\hline \multicolumn{11}{|l|}{ Annonaceae } \\
\hline Annona coriacea Mart. & - & - & - & - & - & - & 4 & - & - & - \\
\hline Annona emarginata (Schltdl.) H. Rainer & 2 & - & - & - & - & - & - & - & - & - \\
\hline Annona sylvatica A. St.-Hil. & 8 & - & - & - & 1 & - & - & - & - & 1 \\
\hline \multicolumn{11}{|l|}{ Apocynaceae } \\
\hline Aspidosperma tomentosum Mart. \& Zucc. & - & - & - & - & - & - & 1 & - & - & - \\
\hline Tabernaemontana catharinensis A. DC. & - & 1 & - & - & 1 & 2 & 6 & - & - & - \\
\hline \multicolumn{11}{|l|}{ Araliaceae } \\
\hline Dendropanax cuneatus (DC.) Decne. \& Planch. & - & 2 & - & - & - & - & - & - & - & - \\
\hline Schefflera calva (Cham.) Frodin \& Fiaschi & - & - & - & - & - & 3 & 2 & - & - & - \\
\hline Sciadodendrom excelsum Griseb. & - & - & 1 & - & - & - & - & - & - & - \\
\hline \multicolumn{11}{|l|}{ Arecaceae } \\
\hline Syagrus romanzoffiana (Cham.) Glassman & - & 3 & - & - & - & - & - & - & - & - \\
\hline \multicolumn{11}{|l|}{ Asteraceae } \\
\hline Chromolaena laevigata (Lam.) R.M.King \& H.Rob. & - & - & - & - & - & - & - & 11 & - & - \\
\hline Moquiniastrum polymorphum (Less.) G. Sancho & - & - & - & - & - & - & - & - & - & 3 \\
\hline Porophyllum ruderale (Jacq.) Cass. & - & - & - & - & - & - & - & 2 & - & - \\
\hline Vernonanthura brasiliana (L.) H. Rob. & 2 & 2 & - & - & - & 2 & 11 & 32 & - & - \\
\hline $\begin{array}{l}\text { Vernonanthura polyanthes (Spreng.) A.J. Vega \& M. } \\
\text { Dematt. }\end{array}$ & - & 1 & - & - & - & - & - & - & 1 & - \\
\hline
\end{tabular}

Bignoniaceae

Handroanthus chrysotrichus (Mart. ex A. DC.) Mattos Standl.

Handroanthus impetiginosus (Mart. ex DC.) Mattos Jacaranda cuspidifolia Mart.

Tabebuia roseoalba (Ridl.) Sandwith

Tecoma stans (L.) Juss. ex Kunth.

Zeyheria tuberculosa (Vell.) Bureau

Boraginaceae

Cordia superba Cham. 
Tabela 7 (continuação)

\begin{tabular}{|c|c|c|c|c|c|c|c|c|c|c|}
\hline Família/Espécie & $\mathrm{P} 1$ & $\mathrm{P} 2$ & $\mathrm{P} 3$ & $\mathrm{P} 4$ & P5 & P6 & $\mathrm{P} 7$ & P8 & P9 & $\mathrm{P} 10$ \\
\hline Cordia trichotoma (Vell.) Arráb. ex Steud. & - & - & - & - & - & 1 & - & - & - & - \\
\hline Varronia polycephala Lam. & - & 13 & - & - & - & - & - & - & - & - \\
\hline \multicolumn{11}{|l|}{ Cannabaceae } \\
\hline Trema micrantha (L.) Blume & - & - & - & - & - & - & - & 1 & - & 1 \\
\hline \multicolumn{11}{|l|}{ Caricaceae } \\
\hline Carica papaya $\mathrm{L}$. & - & - & 2 & - & - & - & - & - & - & - \\
\hline \multicolumn{11}{|l|}{ Dilleniaceae } \\
\hline Doliocarpus dentatus (Aubl.) Standl. & - & - & 1 & - & - & 10 & - & - & - & - \\
\hline \multicolumn{11}{|l|}{ Equisetaceae } \\
\hline Equisetum giganteum $\mathrm{L}$. & - & - & - & - & - & - & 61 & - & - & - \\
\hline \multicolumn{11}{|l|}{ Euphorbiaceae } \\
\hline Alchornea glandulosa Poepp. \& Endl. & - & - & 3 & - & - & - & - & - & 1 & \\
\hline Alchornea triplinervia (Spreng.) Müll. Arg. & - & - & - & - & 2 & - & - & - & - & - \\
\hline Croton floribundus Spreng. & 5 & - & 2 & 22 & 4 & - & - & - & 1 & 9 \\
\hline Croton urucurana Baill. & 2 & 5 & 3 & - & 1 & - & - & 4 & - & - \\
\hline Mabea fistulifera Mart. & - & - & - & - & 37 & - & - & 2 & - & - \\
\hline Ricinus communis L. & - & 5 & - & - & - & - & - & - & - & - \\
\hline
\end{tabular}

Fabaceae

Anadenanthera macrocarpa (Benth.) Brenan

Bauhinia forficata Link

Bauhinia pentandra (Bang.) Vogel ex Stend.

Copaifera langsdorffii Desf.

Centrolobium robustum (Vell.) Mart. ex Benth.

Dipteryx alata Vogel

Enterolobium contortisiliquum (Vell.) Morong

Inga capitata Desv.

Inga marginata Willd.

Inga sesselis (Vell.) Mart.

Inga striata Benth.

Hymenaea courbaril $\mathrm{L}$.

Leucaena leucocephala (Lam.) de Wit

Machaerium villosum Vogel

Mimosa bimucronata (DC.) Kuntze

Myroxylon peruiferum $\mathrm{L}$. $\mathrm{f}$.

Parapiptadenia rigida (Benth.) Brenan

Peltophorum dubium (Spreng.) Taub.

Piptadenia gonoacantha (Mart.) J.F. Macbr.

Poincianella pluviosa (D.C.) L.P. Queiroz.

Pterocarpus rohrii Vahl

Schizolobium parahyba (Vell.) S.F. Blake

Senegalia polyphylla (DC.) Britton 
Tabela 7 (continuação)

\begin{tabular}{l} 
Família/Espécie \\
\hline Senna alata (L.) Roxb. \\
Senna pendula (Humb. \& Bonpl. ex Willd.) H.S. Irwin \& \\
Barneby
\end{tabular}

Heliconiaceae

Heliconia rostrata Ruiz \& Pav.

$\begin{array}{llllllllll}\text { P1 } & \text { P2 } & \text { P3 } & \text { P4 } & \text { P5 } & \text { P6 } & \text { P7 } & \text { P8 } & \text { P9 } & \text { P10 }\end{array}$

Lauraceae

Nectandra lanceolata Nees \& Mart.

Nectandra megapotamica (Spreng.) Mez

Ocotea pulchella (Nees \& Mart.) Mez

Lecythidaceae

Cariniana estrellensis (Raddi) Kuntze

Lythraceae

Lafoensia pacari A. St.-Hil.

Malvaceae

Apeiba tibourbou Aubl.

Ceiba speciosa (A. St.-Hil.) Ravenna

Christiana macrodon Toledo

Guazuma ulmifolia Lam.

Helicteres ovata Lam.

Heliocarpus popayanensis Kunth

Luehea candicans Mart.

Luehea divaricata Mart.

Luehea grandiflora Mart.

Sida cordifolia L.

Sida rhombifolia L.

Triumfetta semitriloba Jacq.

Urena lobata L.

Melastomataceae

Miconia discolor DC.

Meliaceae

Cabralea canjerana (Vell.) Mart.

Cedrela fissilis Vell.

Cedrela odorata L.

Guarea guidonia (L.) Sleumer

Moraceae

Ficus guaranitica Chodat

Ficus obtusifolia Kunth

Myrtaceae

Eugenia florida DC.

Eugenia ligustrina (Sw.) Willd.

Eugenia pyriformis Cambess.

Eugenia uniflora L. 
Tabela 7 (continuação)

\begin{tabular}{|c|c|c|c|c|c|c|c|c|c|c|}
\hline Família/Espécie & $\mathrm{P} 1$ & $\mathrm{P} 2$ & $\mathrm{P} 3$ & $\mathrm{P} 4$ & $\mathrm{P} 5$ & P6 & $\mathrm{P} 7$ & P8 & P9 & $\mathrm{P} 10$ \\
\hline Myrciaria floribunda (H. West ex Willd.) O. Berg & - & - & - & - & - & - & - & - & - & 1 \\
\hline Myrciaria glomerola O.Berg. & - & - & - & - & - & - & 1 & - & - & - \\
\hline Myrcia splendens (Sw.) DC. & - & - & - & - & - & - & - & - & 2 & 2 \\
\hline Psidium cattleianum Sabine & - & - & 1 & - & 2 & - & - & - & 2 & - \\
\hline Psidium guajava $\mathrm{L}$. & 1 & 1 & 12 & - & - & 6 & - & 1 & - & - \\
\hline Psidium guineense Sw. & - & - & - & - & - & - & - & - & 2 & - \\
\hline \multicolumn{11}{|l|}{ Phytolaccaceae } \\
\hline Galessia integrifolia (Spreng.) Harms. & 1 & - & - & - & - & - & - & - & - & - \\
\hline Seguieria langsdorffii Moq. & 1 & 1 & - & - & - & - & - & - & - & - \\
\hline \multicolumn{11}{|l|}{ Piperaceae } \\
\hline Piper aduncum L. & 13 & 85 & 20 & - & - & 2 & 9 & - & 4 & 10 \\
\hline Piper amalago $\mathrm{L}$. & - & 12 & 49 & - & - & - & - & - & 1 & - \\
\hline Piper arboreum Aubl. & - & - & 2 & - & - & 2 & - & - & - & - \\
\hline Piper gaudichaudianum Kunth & - & - & - & - & - & - & - & - & - & 14 \\
\hline Piper glabratum Kunth & - & 10 & 29 & - & - & - & - & - & - & - \\
\hline Piper umbellatum L. & - & 48 & 11 & - & - & - & - & - & - & - \\
\hline \multicolumn{11}{|l|}{ Poaceae } \\
\hline Lasiacis ligulata Hitchc. \& Chase & - & - & - & - & 4 & - & 1 & - & - & - \\
\hline \multicolumn{11}{|l|}{ Polygonaceae } \\
\hline Triplaris americana $\mathrm{L}$. & - & 5 & - & - & 1 & 10 & - & - & - & - \\
\hline \multicolumn{11}{|l|}{ Primulaceae } \\
\hline Myrsine gardneriana A.DC. & - & - & - & - & - & - & - & - & 1 & 2 \\
\hline Myrsine guianensis (Aubl.) Kuntze & - & - & - & 5 & - & - & 12 & - & - & - \\
\hline Myrsine umbellata G. Don & 3 & - & - & - & - & 3 & - & - & - & - \\
\hline \multicolumn{11}{|l|}{ Rhamnaceae } \\
\hline Colubrina glandulosa Perkins & 1 & 1 & 12 & - & - & - & - & 2 & - & - \\
\hline Rhamnidium elaeocarpum Reissek & - & 3 & - & - & - & - & - & - & - & - \\
\hline \multicolumn{11}{|l|}{ Rubiaceae } \\
\hline Coutarea hexandra (Jacq.) K. Schum. & - & - & - & - & - & - & - & - & - & 1 \\
\hline Genipa americana $\mathrm{L}$. & - & - & - & - & - & 4 & - & - & - & - \\
\hline Psychotria mapourioides DC. & - & 1 & - & - & - & - & - & - & - & - \\
\hline \multicolumn{11}{|l|}{ Rutaceae } \\
\hline Zanthoxylum rhoifolium Lam. & - & - & - & - & - & - & - & - & - & 1 \\
\hline \multicolumn{11}{|l|}{ Salicaceae } \\
\hline Casearia sylvestris $\mathrm{Sw}$. & - & - & - & - & - & - & 1 & - & 1 & 3 \\
\hline \multicolumn{11}{|l|}{ Sapindaceae } \\
\hline Allophylus edulis (A.St.-Hil.) Hieron.ex Niederl & - & - & - & - & - & - & - & - & 22 & - \\
\hline Cupania vernalis Cambess. & - & - & - & - & 2 & - & - & - & - & - \\
\hline Dilodendron bipinnatum Radlk. & - & - & 1 & - & - & - & - & - & - & - \\
\hline Sapindus saponaria $\mathrm{L}$. & 1 & - & - & - & 1 & - & - & - & - & - \\
\hline Serjania caracasana (Jacq.) Willd & 1 & - & - & - & - & 5 & - & - & 7 & 1 \\
\hline
\end{tabular}

Solanaceae 
Tabela 7 (continuação)

\begin{tabular}{|c|c|c|c|c|c|c|c|c|c|c|}
\hline Família/Espécie & $\mathrm{P} 1$ & $\mathrm{P} 2$ & $\mathrm{P} 3$ & $\mathrm{P} 4$ & P5 & $\mathrm{P} 6$ & $\mathrm{P} 7$ & P8 & P9 & $\mathrm{P} 10$ \\
\hline Cestrum mariquitense Kunth & 17 & 15 & - & - & 1 & 1 & 1 & - & 2 & - \\
\hline Cestrum strigilatum Ruiz \& Pav & - & - & - & - & - & - & 2 & - & - & - \\
\hline Solanum americanum Mill. & - & - & - & - & - & - & 2 & - & - & - \\
\hline Solanum argenteum Dunal & - & 1 & - & - & - & - & - & - & - & - \\
\hline Solanum caavurana Vell. & - & 1 & - & - & - & - & - & - & - & - \\
\hline Solanum granulosoleprosum Dunal & - & - & - & - & - & - & - & - & - & 9 \\
\hline Solanum mauritianum Scop. & - & - & 4 & - & - & - & - & - & - & - \\
\hline Solanum pseudoquina A.St.-Hil. & - & - & - & - & - & - & - & - & - & 1 \\
\hline \multicolumn{11}{|l|}{ Styraceae } \\
\hline Styrax pohlii A.DC. & - & - & - & - & - & - & - & - & 1 & - \\
\hline \multicolumn{11}{|l|}{ Urticaceae } \\
\hline Cecropia pachystachya Trécul & 19 & 3 & 19 & - & - & 1 & 5 & 7 & - & - \\
\hline \multicolumn{11}{|l|}{ Verbenaceae } \\
\hline Aloysia virgata (Ruiz \& Pav.) Pers. & 1 & - & - & - & - & - & - & 41 & - & - \\
\hline Citharexylum myrianthum Cham. & - & - & - & 14 & - & - & - & - & - & - \\
\hline Lantana camara $\mathrm{L}$. & - & 1 & - & - & - & 1 & - & - & - & - \\
\hline \multicolumn{11}{|l|}{ Violaceae } \\
\hline Hybanthus atropurpureus (A. St.-Hil.) Taub. & - & - & - & - & - & - & - & - & - & 56 \\
\hline Total de Espécies & 41 & 40 & 31 & 20 & 27 & 25 & 25 & 16 & 26 & 24 \\
\hline Total de Indivíduos & 191 & 339 & 326 & 282 & 148 & 111 & 196 & 244 & 105 & 154 \\
\hline
\end{tabular}

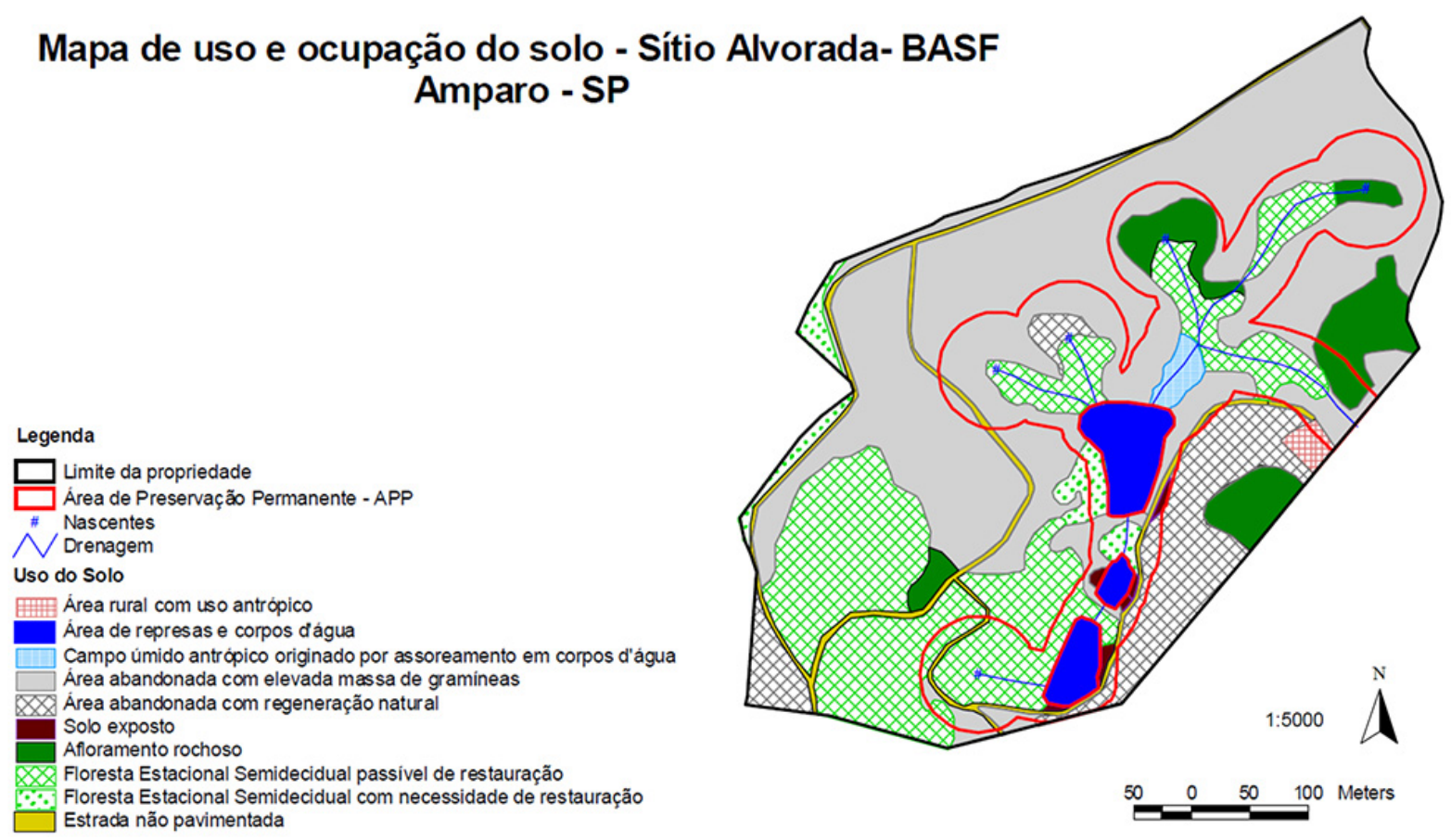

Figura 4. Mapa de uso e ocupação do solo de uma das áreas da Estação Experimental Agrícola da BASF, Amparo, SP, Brasil. Imagem disponibilizada por Tiago Egydio Barreto.

Figure 4. Map of land use and occupation of one of the areas of the BASF Agricultural Experimental Station, Amparo, SP, Brazil. Image provided by Tiago Egydio Barreto. 
Tabela 8. Resultados dos indicadores ecológicos avaliados em campo das dez propriedades rurais sorteadas, que participaram do PAAA no Estado de São Paulo, Brasil.

Table 8. Results of the ecological indicators evaluated in the field of the ten selected rural properties, which participated in the PAAA in the State of São Paulo, Brazil.

\begin{tabular}{|c|c|c|c|c|}
\hline $\begin{array}{l}\text { Empresa/ Idade do } \\
\text { plantio }\end{array}$ & $\begin{array}{l}\text { Cobertura do solo } \\
\text { com vegetação } \\
\text { nativa }(\%)\end{array}$ & $\begin{array}{l}\text { Número de } \\
\text { espécies nativas } \\
\text { regenerantes }\end{array}$ & $\begin{array}{l}\text { Densidade de } \\
\text { indivíduos nativos } \\
\text { regenerantes } \\
\left(\mathrm{n}^{\mathrm{o}} \text {. ind./ha.) }\right.\end{array}$ & Recomendações \\
\hline $\begin{array}{l}\text { Usina da Pedra S/A - } \\
13 \text { anos }\end{array}$ & $\begin{array}{c}52,0 \\
\text { (mínimo) }\end{array}$ & $\begin{array}{c}41 \\
\text { (adequado) }\end{array}$ & $\begin{array}{c}1.910 \\
\text { (mínimo) }\end{array}$ & $\begin{array}{l}\text { Plantio de adensamento com } \\
\text { espécies de recobrimento }\end{array}$ \\
\hline $\begin{array}{l}\text { Usina São João - } 14 \\
\text { anos }\end{array}$ & $\begin{array}{c}54,4 \\
\text { (mínimo) }\end{array}$ & $\begin{array}{c}40 \\
\text { (adequado) }\end{array}$ & $\begin{array}{c}3.390 \\
\text { (adequado) }\end{array}$ & $\begin{array}{l}\text { Plantio de adensamento com } \\
\text { espécies de recobrimento }\end{array}$ \\
\hline $\begin{array}{c}\text { Usina Batatais - } 12 \\
\text { anos }\end{array}$ & $\begin{array}{c}90,2 \\
\text { (adequado) }\end{array}$ & $\begin{array}{c}31 \\
\text { (adequado) }\end{array}$ & $\begin{array}{c}3.260 \\
\text { (adequado) }\end{array}$ & $\begin{array}{l}\text { Manutenção do isolamento } \\
\text { dos fatores de degradação e } \\
\text { monitoramento periódico. }\end{array}$ \\
\hline Usina Lins - 8 anos & $\begin{array}{c}86,4 \\
\text { (adequado) }\end{array}$ & $\begin{array}{c}20 \\
\text { (adequado) }\end{array}$ & $\begin{array}{c}2.820 \\
\text { (adequado) }\end{array}$ & $\begin{array}{l}\text { Manutenção do isolamento } \\
\text { dos fatores de degradação e } \\
\text { monitoramento periódico. }\end{array}$ \\
\hline $\begin{array}{l}\text { Estação Experimental } \\
\text { Anhembi - } 11 \text { anos }\end{array}$ & $\begin{array}{c}87,5 \\
\text { (adequado) }\end{array}$ & $\begin{array}{c}27 \\
\text { (adequado) }\end{array}$ & 1.480 (mínimo) & $\begin{array}{l}\text { Plantio de adensamento com } \\
\text { espécies de recobrimento }\end{array}$ \\
\hline $\begin{array}{l}\text { Usina Colombo - } 8 \\
\text { anos }\end{array}$ & $\begin{array}{c}88,5 \\
\text { (adequado) }\end{array}$ & $\begin{array}{c}25 \\
\text { (adequado) }\end{array}$ & $\begin{array}{c}1.110 \\
\text { (adequado) }\end{array}$ & $\begin{array}{c}\text { Manutenção do isolamento } \\
\text { dos fatores de degradação e } \\
\text { monitoramento periódico. }\end{array}$ \\
\hline $\begin{array}{l}\text { Usina Branco Peres - } \\
10 \text { anos }\end{array}$ & $\begin{array}{c}88,0 \\
\text { (adequado) }\end{array}$ & $\begin{array}{c}25 \\
\text { (adequado) }\end{array}$ & $\begin{array}{c}1.960 \\
\text { (mínimo) }\end{array}$ & $\begin{array}{l}\text { Plantio de adensamento com } \\
\text { espécies de recobrimento }\end{array}$ \\
\hline $\begin{array}{l}\text { Usina Moema - } 8 \\
\text { anos }\end{array}$ & $\begin{array}{c}91,0 \\
\text { (adequado) }\end{array}$ & $\begin{array}{c}16 \\
\text { (mínimo) }\end{array}$ & $\begin{array}{c}2.440 \\
\text { (adequado) }\end{array}$ & $\begin{array}{l}\text { Manutenção do isolamento } \\
\text { dos fatores de degradação e } \\
\text { monitoramento periódico. }\end{array}$ \\
\hline $\begin{array}{l}\text { Estação Experimental } \\
\text { Santo Antônio de } \\
\text { Posse - } 12 \text { anos }\end{array}$ & $\begin{array}{c}98,5 \\
\text { (adequado) }\end{array}$ & $\begin{array}{c}26 \\
\text { (adequado) }\end{array}$ & $\begin{array}{c}1.050 \\
\text { (mínimo) }\end{array}$ & $\begin{array}{l}\text { Plantio de adensamento com } \\
\text { espécies de recobrimento }\end{array}$ \\
\hline $\begin{array}{l}\text { Sítio Alvorada - } \\
\text { BASF/2008 }\end{array}$ & $\begin{array}{c}83,0 \\
\text { (adequado) }\end{array}$ & $\begin{array}{c}24 \\
\text { (adequado) }\end{array}$ & $\begin{array}{c}1.540 \\
\text { (mínimo) }\end{array}$ & $\begin{array}{l}\text { Plantio de adensamento com } \\
\text { espécies de recobrimento }\end{array}$ \\
\hline
\end{tabular}

Avaliação dos benefícios socioeconômicos, diretos e indiretos, provenientes do Programa de Adequação Ambiental e Agrícola - As respostas referentes ao questionário socioeconômico foram agrupadas para avaliação dos possíveis benefícios obtidos com a inserção do PAAA. Nas dez propriedades selecionadas, que perfazem $38 \%$ dos PAAAs do LERF no Estado de São Paulo, foi constatado que estas dez empresas empregam um total de 140 funcionários, envolvidos exclusivamente com o cumprimento do programa.

Verificou-se ainda que o salário desses trabalhadores é, em média, de $\mathrm{R} \$ 1.980,00$, considerando os encargos sociais e trabalhistas. Aponte-se que o rendimento salarial mensal médio per capita no Estado de São Paulo é de dois salários mínimos (IBGE 2017), averiguou-se assim que o pagamento dos trabalhadores destas empresas é abaixo do valor da média salarial no Estado de São Paulo visto que, quando desconsiderados estes encargos sociais e trabalhistas, o rendimento salarial médio destes funcionários envolvidos com o cumprimento destes programas corresponde a um valor próximo ao de um salário mínimo.

Seis empresas têm como política doar parte de sua produção de mudas a outras propriedades da região. Essa doação correspondeu aos excedentes de cada projeto dessas empresas, de modo a evitar seu descarte. Assim, o número de mudas doadas às propriedades fora de cada PAAA teve uma variação entre 16.000 a 120.000 mudas por programa, conforme a produção excedente anual do projeto de cada viveiro.

É importante considerar, nesse universo, o papel da regeneração natural reocupando as áreas agrícolas de menor 
degradação, pois nessas áreas não foi planejado o plantio de mudas no programa de adequação ambiental, já que a metodologia indicada foi a restauração passiva.

Nesse contexto, retomamos a fala de um dos gestores ambientais, que informou que o objetivo inicial da empresa em que presta serviços era o plantio total de um milhão de mudas, entretanto, esse plantio total não foi necessário, tendo em vista a regeneração natural expressiva que ocorreu na área de atuação da empresa.

Posto isso, ressaltamos aqui a importância do diagnóstico prévio bem feito, para definição de metodologias mais adequadas de restauração de cada situação de degradação e do monitoramento periódico desses plantios de restauração florestal, pois essa avaliação permite a definição e redefinição das metodologias de restauração mais adequadas a serem empregadas em cada etapa do processo (Souza et al. 2018).

O potencial de regeneração natural como estratégia de recuperação florestal mostrou-se, em uma das propriedades atendidas pelo PAAA, como um importante método de restauração. Assim, vale ressaltar que isso trouxe benefícios tanto em relação à efetividade, quanto aos custos do programa (Mangueira et al. 2019).

Os funcionários envolvidos com o cumprimento de quatro dos dez PAAAs recebem treinamento com regularidade, que varia de semestral a anual, de modo a assegurar a correta execução e monitoramento do programa. Por sua vez, em outros seis PAAAs não foi oferecido treinamento periódico em relação à execução adequada do programa aos seus funcionários. Um dos gestores ambientais dessas empresas justificou que a não manutenção de treinamentos periódicos dos funcionários deve-se à recente mudança na equipe gestora.

Ressalta-se aqui a importância do acompanhamento dos programas, conforme é recomendado no próprio PAAA, para a verificação de seu andamento de forma adequada (Rodrigues et al. 2007b, Rodrigues et al. 2016).

A ausência de treinamentos periódicos para assegurar a correta implantação e execução dos PAAAs em seis destas propriedades evidencia a importância do monitoramento contínuo dessas áreas, pois a ausência de capacitação pode comprometer, desde a execução das ações do programa, como o sucesso dessas ações de restauração florestal em campo (SMA 2014, Viani et al. 2017).

São desenvolvidas também, nesses programas, atividades regulares de educação ambiental com seus funcionários. As intervenções envolvem palestras sobre sustentabilidade, reconhecimento e controle dos aspectos e impactos ambientais, formas de prevenção/mitigação à poluição ambiental, conhecimento e respeito à fauna $\mathrm{e}$ à flora, uso racional de recursos naturais e desempenho ambiental sustentável. São realizados, ainda, treinamentos relacionados ao PAAA e à coleta seletiva de resíduos.

Em nenhuma das dez propriedades são desenvolvidas, atualmente, as atividades de visitação às trilhas de interpretação ambiental com fins educativos, prática inicialmente recomendada por ser uma das etapas propostas no próprio PAAA, visto que estas trilhas interpretativas foram construídas e eram realizadas visitações a estas áreas no início da implantação do programa nestas propriedades (Rodrigues et al. 2007a), mas esta prática foi interrompida por motivos diversos.

A reativação das atividades educacionais nas trilhas interpretativas visa também a fornecer subsídios para a recuperação e conservação da biodiversidade, contribuindo assim para a formação de uma consciência ambiental acerca da importância de se preservar a biodiversidade regional (Gamboa et al. 2009), sobretudo na Mata Atlântica, onde remanescem somente $16,3 \%$ de sua cobertura vegetal original (Hirota 2019).

Nesse cenário, recomendou-se aos gestores a retomada dessa importante etapa do programa, pois essa prática permitirá ampliar o potencial de sensibilização dos proprietários rurais, dos funcionários, de familiares e dos demais visitantes dessas trilhas para o entendimento da importância da conservação e restauração dos remanescentes florestais e de seus serviços ecossistêmicos, o que irá resultar na divulgação da importância dos ganhos ambientais e socioeconômicos advindos da manutenção da cobertura vegetal remanescente nesses locais (Carvalho 2008). Assim, irá potencializar a implantação e perpetuação em larga escala das ações de restauração florestal estabelecidas em cada propriedade.

Cabe ressaltar ainda a importância da certificação ambiental destas empresas, obtida por quatro das dez empresas analisadas, o que corresponde a $38 \%$ das propriedades atendidas pelo PAAA do LERF no Estado de São Paulo. O PAAA foi usado para certificação ambiental da área agrícola, com a obtenção dos Certificados Bonsucro e o Protocolo Agroambiental - Etanol Verde.

Neste contexto, uma possibilidade a ser incentivada refere-se à obtenção de certificações ambientais por essas empresas, com a formulação de processos mais inovadores de certificação. Recomenda-se assim, por exemplo, a remuneração dos proprietários por suas ações excedentes ao mínimo previsto em lei de restauração florestal (Aronson et al. 2011). Tal recompensa poderia se dar tanto por meio da compensação de RL de outra propriedade, como também por meio de pagamentos pelos serviços ambientais prestados (Brancalion et al. 2013, Latawiec et al. 2015).

Reitera-se aqui que, por meio da regularização ambiental e legal das propriedades, é possível a obtenção de certificação ambiental, que pode resultar na abertura de mercados internacionais para a exportação da produção de açúcar e álcool, por exemplo (Brancalion \& Rodrigues 2010). Essa quebra de barreiras comerciais permitiria a compensação financeira sobre a potencial perda de áreas produtivas (Metzger 2010). Afinal, a produção agrícola mais técnica e em áreas de maior aptidão agrícola trará ganhos cada vez maiores de produtividade no setor, estimando-se que o mesmo nível de produção atual poderá ser obtido em áreas cada vez menores (Rodrigues et al. 2007a, Vidal et al. 2016). 
A certificação ambiental da produção agrícola potencializa assim a criação de novos mercados e incentivos para os produtores rurais, o que leva à redução das taxas de perda da diversidade vegetal remanescente (Newton et al. 2015).

Cabe ressaltar, entre algumas das propriedades que já obtiveram vantagens competitivas com a obtenção de certificações ambientais com a tecnificação de suas atividades agrícolas, os programas de adequação de empresas florestais (Forest Stewardship Council 2015) e de usinas de cana-deaçúcar (Bonsucro 2015), bem como os projetos Pecuária Verde e Pecuária Sustentável (Silva \& Barreto 2014).

Para isso, deve-se favorecer setores das propriedades agrícolas que possam ser destinados a modalidades de uso do solo menos impactantes à biodiversidade e à geração de serviços ecossistêmicos (Brancalion \& Rodrigues 2010, Brancalion et al. 2016).

Diante do exposto, verificou-se que o Programa de Adequação Ambiental e Agrícola implantado em dez propriedades, correspondentes a $38 \%$ das propriedades do PAAA atendidas pelo LERF no Estado de São Paulo, possibilitou a geração de 140 empregos nestas propriedades com o cumprimento do programa. Ainda, averiguou-se que estas empresas adotam práticas adequadas de conservação do solo e que o PAAA permitiu a obtenção da certificação ambiental em quatro destas propriedades, o que poderá ampliar suas vantagens competitivas no mercado e seus ganhos com as ações de restauração florestal.

Adicionalmente, verificou-se que estas empresas mantêm palestras e alguns cursos sobre temáticas relacionadas à educação ambiental, entretanto, atualmente, não desenvolvem a implantação e visitação às trilhas interpretativas educativas.

Neste contexto, é recomendada a retomada desta importante etapa do PAAA, o que irá resultar na perpetuação do conhecimento sobre o Programa de Adequação Ambiental e Agrícola de Propriedades Rurais aos visitantes e demais colaboradores diretos e indiretos na implantação e visitação destas trilhas e, consequentemente, a disseminação das diretrizes desse programa, com fins de conservação ambiental e agrícola.

\section{Conclusões}

Os resultados do Programa de Adequação Ambiental e Agrícola avaliado em cada propriedade permitem subsidiar o fortalecimento da pressão pela criação de novas políticas públicas para potencializar as ações de regularização ambiental e agrícola nestas propriedades, entre elas, a ampliação da criação de políticas públicas que incentivem o pagamento por serviços ambientais aos proprietários que efetivaram a restauração em suas propriedades, a isenção de tributos e a criação de outras formas de incentivos tributários diretamente relacionados ao processo de restauração, com a remuneração paga a produtos e processos oriundos das propriedades que efetuaram ações de restauração florestal.
Por fim, o monitoramento contínuo do Programa de Adequação Ambiental e Agrícola de Propriedades Rurais destas empresas no Estado de São Paulo, com esta abordagem ambiental e socioeconômica, é recomendado, pois irá possibilitar o sucesso da adequação ambiental e agrícola destas propriedades a longo prazo, em larga escala e a um custo reduzido.

\section{Agradecimentos}

Ao Conselho Nacional de Desenvolvimento Científico e Tecnológico, pela bolsa de Mestrado concedida ao primeiro autor (Processo CNPq n ${ }^{\circ} 131325 / 2017-5$ ). Aos pesquisadores Vinícius Castro Souza e Nicoll Escobar, pelo auxílio na identificação do material botânico. Aos gestores ambientais responsáveis pela condução de cada Programa de Adequação Ambiental e Agrícola, por terem cedido gentilmente o seu tempo, permitirem a visitação as áreas em campo e pelos dados disponibilizados. Agradecemos a Alice Maria Salvatore Barbin Laurindo e Tiago Egydio Barreto, respectivamente, pelas sugestões na revisão do artigo e fotos aéreas disponibilizadas. À Fundação de Amparo a Pesquisa do Estado de São Paulo (Processo FAPESP n ${ }^{\circ}$ 13/50718-5).

\section{Literatura citada}

Amazonas, N., Forrester, D.I., Silva, C.C., Almeira, D.R.A., Rodrigues, R.R. \& Brancalion, P.H.S. 2018. High diversity mixed plantations of Eucalyptus and native trees: An interface between production and restoration for the tropics. Forest Ecology and Management 417: 247-256.

Aronson, J., Brancalion, P.H.S., Durigan, G., Rodrigues, R.R., Engel, V.L., Tabarelli, M., Torezan, J.M.D., Gandolfi, S., Melo, A.C.G., Kageyama, P.Y., Marques, C.M., Nave, A.G., Martins, S.V., Gandara, F.B., Reis, A. \& Barbosa, L.M. 2011. What role should government regulation play in ecological restoration: Ongoing debate in São Paulo State, Brazil. Restoration Ecology 19: 690-695.

Ayres, J.M., Fonseca, G.A.B., Rylands, A.B., Queiroz, H.L., Pinto, L.P., Masterson, D. \& Cavalcanti, R.B. 2005. Os corredores ecológicos das florestas tropicais do Brasil. Sociedade Civil Mamirauá, Belém.

Bonsucro. Certified members. 2015. Disponível em http:// www.bonsucro.com/certified-members/ (acesso em 14III-2019).

Brancalion, P.H.S., Cardozo, I.V., Camatta, A., Aronson, J. \& Rodrigues, R.R. 2014. Cultural Ecosystem Services and Popular Perceptions of the Benefits of an Ecological Restoration Project in the Brazilian Atlantic Forest. Restoration Ecology 22: 65-71. 
Brancalion, P.H.S., Gandolfi, S. \& Rodrigues, R.R. 2009. Fase 8: Uma visão ecossistêmica do processo de restauração ecológica. In: Rodrigues, R.R.; Brancalion, P.H.S.; Isernhagen, I. (Orgs.) Pacto pela restauração da mata atlântica: referencial dos conceitos e ações de restauração florestal. LERF/ESALQ/Instituto BioAtlântica, São Paulo, pp.78-85.

Brancalion, P.H.S., Gandolfi, S. \& Rodrigues, R.R. 2015. Restauração Florestal. Oficina de Textos, São Paulo.

Brancalion, P.H.S., Garcia, L.C., Loyola, R., Rodrigues, R.R., Pillar, V.P. \& Lewinsohn, T.M. 2016. A critical analysis of the Native Vegetation Protection Law of Brazil (2012): updates and ongoing initiatives. Brazilian Journal of Nature Conservation 14: 1-15.

Brancalion, P.H.S. \& Rodrigues, R.R. 2010. Implicações do cumprimento do Código Florestal vigente na redução de áreas agrícolas: um estudo de caso da produção canavieira no Estado de São Paulo. Biota Neotropica 10: 565-587.

Brancalion, P.H.S., Viani, R.A.G., Calmon, M., Carrascosa, H. \& Rodrigues, R.R. 2013. How to Organize a Large-Scale Ecological Restoration Program? The Framework Developed by the Atlantic Forest Restoration Pact in Brazil. Journal of Sustainable Forestry 32: 728-744.

Brancalion, P.H.S., Viani, R.A.G., Rodrigues, R.R. \& César, R.G. 2012. Estratégias para auxiliar na conservação de florestas tropicais secundárias inseridas em paisagens alteradas. Boletim Paraense Emílio Goeldi Ciências Naturais 7: 219-234.

Brasil. Decreto no. 23.793, de 23 de janeiro de 1934. Aprova o Código Florestal. 1934. Disponível em https://www. planalto.gov.br/ccivil_03/decreto/1930-1949/D23793. htm (acesso em 11-XII- 2016).

Brasil. Lei $\mathrm{n}^{\mathrm{o}}$ 4.771, de 15 de setembro de 1965. Institui o novo código florestal. 1965. Disponível em http:// www.ambiente.sp.gov.br/legislacao/files/1965/09/ LegislacaoCitada-PL-2364-2007.pdf (acesso em 10XII-2016).

Brasil. Lei n ${ }^{\circ} 12.651$, de 25 de maio de 2012. Dispõe sobre a proteção da vegetação nativa. 2012. Disponível em http:// www.planalto.gov.br/ccivil_03/_ato2011-2014/2012/lei/ 112651.htm (acesso em 1-II-2018).

Brockerhoffi, E.G., Barbaro, L., Castagneyrol, B., Forrester, D.I., Gardiner, B., Gonzalez-Olabarria, J.R., Lyver, P.O.B., Meurisse, N., Oxbrough, A., Taki, H., Thomsom, I.D., Plas, F.V.D. \& Jactel, H. 2017. Forest biodiversity, ecosystem functioning and the provision of ecosystem services. Biodiversity and Conservation 26: 3005-3035.

CAIP - Comitê de Articulação Institucional do Projeto Pacto Xingu. 2016. Plano de recuperação de áreas degradadas do município de São Félix do Xingu (PA). Ministério do Meio Ambiente, Brasília.
Campanili, M. \& Schaffer, W.B. 2010. Mata Atlântica: manual de adequação ambiental. Ministério do Meio Ambiente, Brasília.

Campos, L.M.S. \& Lerípio, A.A. 2009. Auditoria Ambiental: uma ferramenta de gestão. Atlas, São Paulo.

Carvalho, I.C.M. 2008. Educação Ambiental: a formação do sujeito ecológico. Cortez, São Paulo.

Cechinel, A., Fontana, S.A.P., Giustina, K.P.D., Pereira, A.S. \& Prado, S.S. 2016. Estudo/análise documental: uma revisão teórica e metodológica. Revista do Programa de Pós-Graduação em Educação UNESC 5: 1-7.

D’Antônio, C.M. \& Meyerson, L. A. 2002. Exotic plant species as problems and solutions in ecological restoration: A synthesis. Restoration Ecology 10: 703713.

Falkenmark, M., Jägerskog, A. \& Schneider, K. 2014. Overcoming the land-water disconnect in waterscarce regions: time for IWRM to go contemporary. International Journal of Water Resources Development 30: 391-408.

Forest Stewardship Council. 2015. Fatos e números no Brasil e no mundo. Disponível em https://br.fsc.org/ pt-br/fsc-brasil/fatos-e-nmeros (acesso em 18-II-2019).

Gamboa, I., Barretto, V.C.M. \& Xavier, M.V.M. 2009. Implantação de trilha interpretativa em áreas de mata ciliar e cerrado na Universidade Estadual de Goiás, unidade universitária de Ipameri (GO). Espaço em Revista 11: 169-179.

Garcia, L.C., Ellovitch, M.F., Rodrigues, R.R., Brancalion, P.H.S., Matsumoto, M.H., Garcia, F.C., Loyola, R. \& Lewinsohn, T.M. 2016. Análise científica e jurídica das mudanças no Código Florestal, a recente Lei de Proteção da Vegetação Nativa. ABECO/Ed. UFMS, Rio de Janeiro.

Gatica-Saavedra, P., Echeverría, C. \& Nelson, C.R. 2017. Ecological indicators for assessing ecological success of forest restoration: a world review. Restoration Ecology 25: 850-857.

Gonçalves, J.L.M. 2009. Cultivo mínimo aumenta produção florestal. Visão Agrícola 9: 183-186.

Haguette, T.M.F. 2001. Metodologias Qualitativas na Sociologia. Vozes, Petrópolis.

Hirota, M.M. (Coord.) 2019. Atlas dos remanescentes florestais da Mata Atlântica. Fundação SOS Mata Atlântica, São Paulo.

Holmgren, P.K., Holmgren, N.H. \& Barnett, J.L.C. 1990. Index Herbariorum. Part 1. The herbaria of the world. 8 ed. New York Botanical Garden / Internacional Association for Plant Taxonomy, Nova York.

Honda, E.A. \& Durigan G. 2017. A restauração de ecossistemas e a produção de água. Hoehnea 44: 315327. 
IBGE - Instituto Brasileiro de Geografia e Estatística. 2017. O Instituto Brasileiro de Geografia e Estatística divulga o rendimento per capita domiciliar em 2017. Disponível em ftp://ftp.ibge.gov.br/Trabalho_e_ Rendimento/Pesquisa_Nacional_por_Amostra_de_ Domicilios_continua/Renda_domiciliar_per_capita/ Renda_domiciliar_per_capita_2017.pdf (acesso em 30-III- 2018).

Instituto Florestal. 2020. Novo Inventário Florestal do Estado de São Paulo. Disponível em https:// www.infraestruturameioambiente.sp.gov. br/2020/08/novo-inventario-florestal-do-esp-apontacrescimento-de-214-mil-hectares-de-vegetacaonativa-no-territorio-paulista/\#: : text $=0 \% 20$ novo $\% 20$ Invent $\% \mathrm{C} 3 \% \mathrm{~A} 1$ rio $\% 20 \mathrm{Floresta} 1 \% 20$ divulgado, $\% 2 \mathrm{C} 9 \% 25 \% 20 \mathrm{do} \% 20$ territ $\% \mathrm{C} 3 \% \mathrm{~B} 3$ rio $\% 20$ paulista. (acesso em 30-III-2020).

Isernhagen, I., Brancalion, P.H.S., Rodrigues, R.R., Nave, A.G. \& Gandolfi, S. 2009. Diagnóstico ambiental das áreas a serem restauradas visando a definição de metodologias de restauração florestal. In: Rodrigues, R.R., Brancalion, P.H.S., Isernhagen, I. (Orgs.) Pacto pela restauração da mata atlântica: referencial dos conceitos e ações de restauração florestal. LERF/ESALQ-Instituto BioAtlântica, São Paulo.

Joly, C.A., Casatti, L., Brito, M.C.W., Menezes, N.A., Rodrigues, R.R. \& Bolzani, V.S. 2008. Histórico do Programa BIOTA/FAPESP - O Instituto Virtual da Biodiversidade. In: Rodrigues, R.R., Bonini, V. (Orgs.). Diretrizes para a conservação e restauração da biodiversidade no Estado de São Paulo. SMA/Instituto de Botânica, São Paulo.

Lamonato, F.H.F., Farah, F.T., Nave, A.G., Gandolfi, S. \& Rodrigues, R.R. 2016. Restauração florestal de Áreas de Preservação Permanente (APPs) em propriedades de pecuária, no domínio da Mata Atlântica e Amazônia. In: Palhares, J.C.P. (Org.). Produção animal e recursos hídricos. Cubo, São Carlos.

Latawiec, A.E., Strassburg, B.B.N., Brancalion, P.H.S., Rodrigues, R.R. \& Gardner, T. 2015. Creating space for large-scale restoration in tropical agricultural landscapes. Frontiers in Ecology and the Environment 13: 211-218.

Lima, R.C.A. \& Munhoz, L. 2016. Programas de Regularização Ambiental (PRAs): um guia para orientar e impulsionar o processo de regulamentação dos PRAs nos Estados brasileiros. Agroicone, São Paulo.

Mangueira, J.R.S.A., Holl, K.D.H. \& Rodrigues, R.R. 2019. Enrichment planting to restore degraded tropical forest fragments in Brazil. Ecosystems and People 15: 3-10.

Maria, I.C.D. \& Peche-Filho, A. 2009. Terraceamento complementa proteção da superfície. Visão Agrícola 10: $140-143$.
Maury, C.M. (Org.). 2002. Avaliação e identificação de áreas e ações prioritárias para conservação, utilização sustentável e repartição dos benefícios da biodiversidade nos biomas brasileiros. Ministério do Meio Ambiente/ SBF, Distrito Federal.

Metzger, J.P. 2010. O Código Florestal tem Base Científica? Natureza \& Conservação 8: 92-99.

Myers, N., Mittermeier, R.A., Mittermeier, C.G., Fonseca, G.A.B. \& Kent, J. 2000. Biodiversity hotspots for conservation priorities. Nature 403: 853-858.

Nave, A.G., Brancalion, P.H.S., Coutinho, E. \& César, R.G. 2009. Descrição das ações operacionais de restauração. In: Rodrigues, R.R., Brancalion, P.H.S., Isernhagen, I. (Orgs.) Pacto pela restauração da mata atlântica: referencial dos conceitos e ações de restauração florestal. LERF/ESALQ-Instituto BioAtlântica, São Paulo.

Newton, P., Alves-Pinto, H.N. \& Guedes Pinto, L.F. 2015. Certification, Forest Conservation, and Cattle: Theories and Evidence of Change in Brazil. Conservation Letters 8: 206-213.

Pacto pela Restauração da Mata Atlântica. 2013. Protocolo de Monitoramento para Programas e Projetos de Restauração Florestal. Disponível em http://media.wix.com/ugd/5da841_ c228aedb71ae4221bc95b909e0635257.pdf (acesso em 20-II-2017).

Pinto, S.R., Melo, F., Tabarelli, M., Padovesi, A., Mesquita, C.A., Scaramuzza, C.A.M., Castro, P., Carrascosa, H., Calmon, M., Rodrigues, R.R., César, R.G. \& Brancalion, P.H.S. 2014. Governing and Delivering a Biome-Wide Restoration Initiative: The Case of Atlantic Forest Restoration Pact in Brazil. Forests 5: 2212-2229.

Ramos, V.S., Durigan, G., Franco, G.A.D.C., Siqueira, M.F. \& Rodrigues, R.R. 2008. Árvores da Floresta Estacional Semidecidual: guia de identificação de espécies. Editora da Universidade de São Paulo / Biota FAPESP, São Paulo.

Reis, A., Bechara, F.C., Espíndola, M.B., Vieira, N.K. \& Souza, L.L. 2003. Restauração de áreas degradadas: a nucleação como base para incrementar os processos sucessionais. Natureza \& Conservação 1: 28-36.

Rodrigues, R.R., Gandolfi, S., Nave, A.G. \& Attanasio, C.M. 2007a. Adequação ambiental de propriedades agrícolas. In: Fundação Cargill (Coord.) Manejo ambiental e restauração de áreas degradadas. Fundação Cargill, São Paulo.

Rodrigues, R.R., Gandolfi, S., Nave, A.G. \& Attanasio, C.M. 2007b. Atividades de adequação ambiental e restauração florestal do LERF/ESALQ/USP. Pesquisa Florestal Brasileira 55: pp. 7-21. 
Rodrigues, R.R., Farah, F.T., Nave, A.G., Brancalion, P.H.S. \& Gandolfi, S. 2016. A Restauração Florestal na Paisagem por meio do Programa de Adequação Ambiental e Agrícola de Propriedades Rurais. In: Moraes, M.A. (Org.) Restauração de paisagens e florestas no Brasil. UICN, Brasília.

Rodrigues, R.R., Lamonato, F.H.F., Farah, F.T., Nave, A.G. \& Gandolfi, S. 2017. Restauración del bosque de galería bajo reserva legal en propiedades rurales. In: Mazón, M.; Juan Maita, J. \& Aguirre, N. (Eds.) Restauración del paisaje en Latinoamérica: experiências y perspectivas futuras. Memorias del Primer Crongreso Ecuatoriano de Restauración del Paisaje, Quito: Universidad Nacional de Loja y Condesan, pp. 210-231.

Rother, D.C., Vidal, C.Y., Fagundes, I.C., Silva, M.M., Gandolfi, S., Rodrigues, R.R., Nave, A.G.; Viani, R.A. \& Brancalion, P.H.S. 2018. How Legal-Oriented Restoration Programs Enhance Landscape Connectivity? Insights from the Brazilian Atlantic Forest. Tropical Conservation Science 11: 1-9.

Rovere, E.L.L. (Coord.). 2014. Manual de auditoria ambiental. Qualitymark, Rio de Janeiro.

Rozza, A.D.F., Farah, F.T. \& Rodrigues, R.R. 2006. Ecological management of degraded forest fragments. In: Rodrigues, R.R., Martins, S.V., Gandolfi, S. (Eds.). High Diversity Forest Restoration in Degraded Areas: Methods and Projetcs in Brazil. Nova Science Publishers, Nova York.

SER - Society for Ecological Restoration. 2004. The SER International primer on ecological restoration. Disponível em http://www.ser.org/page/SERDocuments. (acesso em 20-II-2018).

Silva, D.S. \& Barreto, P. 2014. O aumento da produtividade e lucratividade da pecuária bovina na Amazônia: o caso do Projeto Pecuária Verde em Paragominas. IMAZON, Belém.

Silva, F.R., Montoya, D., Furtado, R., Memmott, J., Pizo. M.A. \& Rodrigues, R.R. 2015. The restoration of tropical seed dispersal networks. Restoration Ecology $1: 1-9$.
SMA - Secretaria do Meio Ambiente. 2014. Resolução SMA-32, de 03 de Abril de 2014. Estabelece as orientações, diretrizes e critérios sobre restauração ecológica no Estado de São Paulo e dá providências correlatas. Diário Oficial do Estado de São Paulo, Poder Executivo, São Paulo, 03-IV-2014, seção I, pp. 36-37.

Souza, S.C.P.M., Gandolfi, S. \& Rodrigues, R.R. 2018. A influência da cobertura vegetal e da distância do remanescente florestal no processo de regeneração natural na Floresta Ombrófila Densa Montana. Hoehnea 45: 55-68.

Tambosi, L.R., Silva, M.M. \& Rodrigues, R.R. 2012. Adequação ambiental de propriedades rurais e priorização da restauração florestal para otimizar o ganho de conectividade da paisagem. In: Paese, A., Uezu, A., Lorini, M.L., Cunha, A. (Orgs.) Conservação da Biodiversidade com SIG. Oficina de Textos, São Paulo.

Viani, R.A.G., Holl, K.D., Padovezi, A., Strassburg, B.B.N., Farah, F.T., Garcia, L.C., Chaves, R.B., Rodrigues, R.R. \& Brancalion P.H.S. 2017. Protocol for Monitoring Tropical Forest Restoration: Perspectives from the Atlantic Forest Restoration Pact in Brazil. Tropical Conservation Science 10: 1-8.

Vidal, C.Y., Fagundes, I.C., Nave, A.G., Brancalion, P.H.S., Gandolfi, S. \& Rodrigues, R.R. 2014. Adequação ambiental de propriedades rurais e restauração florestal: 14 anos de experiência e novas perspectivas. In: Sambuichi, R.H.R., Silva, A.P.M., Oliveira, M.A.C., Savian, M. (Orgs.) Políticas Agroambientais e Sustentabilidade: desafios, oportunidades e lições aprendidas. IPEA, Brasília.

Vidal, C.Y., Mangueira, J.R., Farah, F.T., Rother, D.C. \& Rodrigues, R.R. 2016. Biodiversity Conservation of Forests and their Ecological Restoration in Highlymodified Landscapes. In: Gheler-Costa, C., Lyra-Jorge, M.C., Verdade, L.M. (Eds.) Biodiversity in Agricultural Landscapes of Southeastern Brazil. De Gruyter Open, Berlim. 